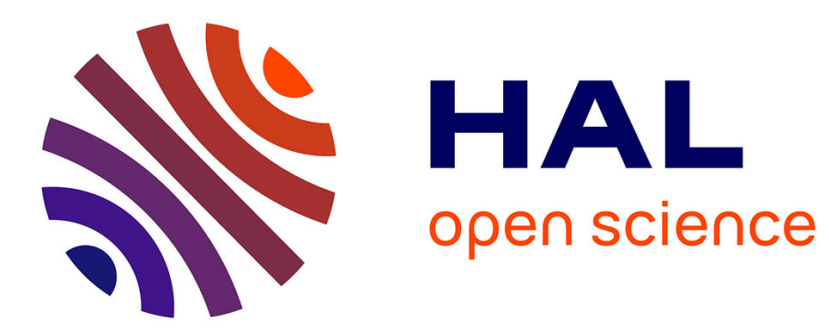

\title{
How do capital structure and economic regime affect fair prices of bank's equity and liabilities?
}

\author{
Donatien Hainaut, Yan Shen, Yan Zeng
}

\section{To cite this version:}

Donatien Hainaut, Yan Shen, Yan Zeng. How do capital structure and economic regime affect fair prices of bank's equity and liabilities?. Annals of Operations Research, 2016, 10.13140/RG.2.1.4662.7921 . hal-01394133

HAL Id: hal-01394133

https://hal-rennes-sb.archives-ouvertes.fr/hal-01394133

Submitted on 8 Nov 2016

HAL is a multi-disciplinary open access archive for the deposit and dissemination of scientific research documents, whether they are published or not. The documents may come from teaching and research institutions in France or abroad, or from public or private research centers.
L'archive ouverte pluridisciplinaire HAL, est destinée au dépôt et à la diffusion de documents scientifiques de niveau recherche, publiés ou non, émanant des établissements d'enseignement et de recherche français ou étrangers, des laboratoires publics ou privés. 


\title{
How do capital structure and economic regime affect fair prices of bank's equity and liabilities?
}

\author{
Donatien Hainaut ${ }^{1}$, Yang Shen $^{2}$, Yan Zeng ${ }^{3}$
}

April 7, 2016

1. ESC Rennes Business School and CREST, France.

2. York University, Toronto, Canada.

3. Lingnan (University) College, Sun Yat-sen University, Guangzhou 510275, P.R. China.

Email: donatien.hainaut@esc-rennes.fr, skyshen87@gmail.com, zengy36@mail.sysu.edu.cn

\begin{abstract}
This paper considers the capital structure of a bank in a continuous-time regime-switching economy. The modeling framework takes into account various categories of instruments, including equity, contingent convertible debts, straight debts, deposits and deposits insurance. Whereas previous researches concentrate on the determination of the capital structure that maximizes shareholders' equity, this work focuses on the fair pricing of liabilities that ensures no cross-subsidization among stakeholders. This is discussed in a case study where the bank's EBIT is modeled by a four-regime process and is fitted to real market data. A numerical analysis reveals that convertible debts can significantly reduce the cost of deposits insurance and straight debts as well as probabilities of bankruptcy. Although it is found that the risk of dilution for shareholders is important, paradoxically, a high conversion rate for the contingent convertible debt, compensated by a low interest cost before conversion, can delay this dilution. Finally, we find that in case of change of economic regime, there exists an optimal capital structure from the shareholder's perspective.
\end{abstract}

Keywords : Contingent convertibles, Regime-switching, Wiener-Hopf factorization, Hitting time.

JEL Classification: J26; G11

\section{Introduction}

Banks issue a wide range of liabilities to finance their investments and nowadays bank managers are faced with the task of minimizing the cost of liabilities, while keeping the risk in the balance sheet under control. In addition to traditional liabilities such as deposits and straight debts, a class of new debt instruments, called contingent convertible bonds, has been issued by banks, especially European banks, since the recent crisis. They provide an automatic recapitalization mechanism in case of insolvency, which hence can be used to mitigate the bankruptcy risk. The market for this type of debts was born in December 2009 with the very first issuance by Lloyds Banking Group. Since then, many other financial institutions, such as UBS, Credit Suisse and Barclays, have issued contingent convertible debts, which are now commonly called CoCo bonds. The yields of CoCos tend to be higher than those of higher-ranked debt instruments of the same issuer. This paper aims at explaining this phenomenon in a regime-switching economy, by analyzing the relationship between the whole capital structure of the bank and the fair costs of deposits, straight debts and contingent convertible bonds.

The optimal capital structure is one of the most important areas in corporate finance, going back to the celebrated MM theorem in Modigliani and Miller (1958). Brennan and Schwartz 
(1978) provide the first quantitative examination of optimal leverage. Myers (1984) reviews some of pitfalls encountered when we try to explain the capital structure of firms. Bradley et al. (1984) propose a model that emphasizes the trade off between tax advantages and bankruptcy costs and its role in the choice of a capital structure. Titman and Wessels (1988) analyze empirically the explanatory power of several theories of optimal capital structure.

In a serie of papers Leland and Toft $(1996)$ or Leland $(1994,1998)$ explore different ways to optimize endogenously the capital structure. In their works, the firm issues perpetual coupon debt that can be called by the equityholders. The equityholders find the optimal default barrier by maximizing the firm value. The main argument justifying this approach is that after the debt being issued, the firm is controlled by equityholders. Titman and Tsyplakov (2007) propose a continuous time model of a firm that can dynamically adjust both its capital structure and its investment choices. Hilberink and Rogers (2002) revisit this model and introduce negative jumps in the asset process. Chen and Kou (2009) extend the Leland-Toft model by introducing two sided jumps in the dynamics of firm assets.

Banks, as financial intermediaries, are different than other firms. Significantly, banks have the unique benefit of being able to issue federally insured debt; but they also bear the cost of strict capital regulations, including the threat of being placed in receivership and wiping out the investment of the shareholders. The optimal capital structure in the banking industry is considered in Pennacchi (2010), who studies the equilibrium pricing of the bank's deposits, contingent capital and shareholders' equity, when the bank's assets follow a jump-diffusion process and the default-free interest rates are stochastic. The work of Koziol and Lawrenz (2012) emphasizes the potential drawbacks of contingent convertibles due to distorted risk incentives. Glasserman and Nouri (2012) derive closed-form expressions for the market value of contingent convertibles when the bank's assets are modeled by a geometric Brownian motion. Barucci and Del Viva (2012) study the optimal capital structure of a bank issuing countercyclical contingent capital. Barucci and Del Viva (2013) extend their previous work to the case with different conversion rules. De Spiegeleer and Schoutens $(2012,2013)$ study CoCo issues with multiple triggers spread across a range of trigger levels. Corcuera et al. (2014) price coupon cancelable CoCo bonds.

In line with Ammann and Genser (2005), Hackbarth et al. (2006) or Koziol and Lawrenz (2012), our paper also considers an EBIT-based capital structure model. However, instead of focusing on the maximization of the firm or equity values, our research focuses on the fair valuation of bank liabilities at issuance. In previous cited papers, the equityholders find the optimal default barrier by maximizing either the firm or the equity values. The main argument justifying this approach is that after the debt being issued, it is the equityholders who control the firm. This optimization criterion does not warranty a fair pricing of debts as the interest rate charge is most of the time assumed exogenous and independent from the capital structure. This is at the origin of a gap between the market value of debts at issuance and the amounts lent by debtholders. For this reason, we opt for an alternative approach in which the fair cost of liabilities is evaluated in a way avoiding cross-subsidization between stakeholders. This allows us next to emphasize the interconnections between the capital structure, cost of deposits, debts, coco bonds and probability of bankruptcy.

On the other hand, except Barucci and Del Viva (2012) considering a two-state economy, almost all previous works do not analyze the effect of macroeconomic conditions or business cycles on the market value of bank's liabilities and equity. However, macroeconomic conditions or business cycles do have significant impacts on the market fundamentals, which should never be ignored in every aspect of finance, such as asset pricing, portfolio selection and risk management. Hamilton (1989) popularizes applications of the so-called regime-switching models in economics and finance. One of the main features of these models is that the parameters in the models are allowed to change over time according to the state of an underlying Markov chain. This provides us with an ideal framework to describe structural changes of macroeconomic conditions or evolutions of business cycles. Indeed, regime-switching models have already received a lot 
of attention in econometrics, asset pricing and allocation. Guidolin and Timmermann (2005) present empirical evidence of persistent 'bull' and 'bear' regimes in UK stock and bond returns. Similar results are found in Guidolin and Timmermann (2008), for international stock markets. Guidolin and Timmermann (2007) characterize investors' asset allocation decisions under a regime-switching model when asset returns are categorized into four states, namely, crash, slow growth, bull and recovery. Cholette et al. (2009) fit skewed-t GARCH marginal distributions for international equity returns and a regime-switching copula. Hainaut and MacGilchrist (2012) study the strategic asset allocation between stocks and bonds when both marginal returns and copula are determined by a hidden Markov chain. Calvet and Fisher $(2001,2004)$ show that the discredited versions of multifractal processes can capture thick tails and have a regime switching structure with a very large number of states. Elliott et al. (2005) develop a regime-switching Esscher transform and consider the pricing of European options.

This paper contributes to the existing literature in several ways. Firstly, it is an extension of Barucci and Del Viva (2012) from a two-regime economy to a multi-regime one. Guidolin and Timmermann (2007) and Gatumel and Ielpo (2011) provide empirical evidences that two regimes are not enough to capture asset returns for many securities and they further point out that a regime economy with two to five states is required to capture the features of each asset's distribution. This is confirmed by the case study in this paper, in which a regime-switching process with two to four states is fitted to real market data. An analysis of loglikelihood, AIC and BIC suggests that the best fit is achieved with four economic states. It should be noted that the results of this paper are not limited to a four-state economy, but work for an economy with any finite number of states. Secondly, this research differentiates with the previous literature in which the discount rate also depends on the economic states. This induces a correlation between the firm's operating profit and the discount rate. Closed-form expressions are established for market values of all bank's liabilities and the deposit insurance. The third contribution is the discussion about the influence of the capital structure on the fair cost of liabilities, which is a guarantee of no cross-subsidization. Finally, this work proposes a method to retrieve probabilities of CoCo conversion and bankruptcy as well as expected times before these events.

We show that convertible debts significantly reduce the cost of deposits insurance and straight debts. CoCo bonds are indeed assimilable to equity and their presence reduces the probability of bankruptcy and credit spreads. Although it is found that the risk of dilution for shareholders is important, paradoxically, a high conversion rate for the contingent convertible debt, compensated by a low interest cost before conversion, can delay this dilution. When liabilities are issued at fair prices, the shareholders' equity has the same market value, whatever the capital structure of the bank. The switching regime model reveals that this is no more the case if the economic conjuncture changes. From the shareholder's perspective, there exists an optimal structure of debts maximizing the equity value in economic regimes, different from the one in force, during the issuance of debts.

The rest of this paper is organized as follows. Section 2 introduces the model for the bank's operating profit and investigates the valuation of the bank's asset under a risk neutral measure chosen by the Esscher transform. Section 3 describes different categories of liabilities and the deposit insurance. In Section 4, properties of hitting times for a Brownian motion with drift and regime-switching are reviewed. Sections 5 and 6 address the evaluation of financial instruments in a two-period setting: before and after conversion of the CoCo debts into equity. In Section 7, an inverse Laplace transform approach is introduced to calculate probabilities of conversion and default. The valuation of fair prices of liabilities is presented in Section 8. Section 9 provides a case study to illustrate our results, and Section 10 concludes the paper. 


\section{Bank's earnings and valuation of asset}

Any bank's operating profit is affected by structural changes of macroeconomic conditions or market modes, which are usually caused by certain events such as wars, natural catastrophes, terrorist attacks, technological innovations as well as economic booms and recessions. To capture this changing feature, a continuous-time Markov chain is adopted to model the economy and is assumed to modulate the risk free rate and other key parameters in the dynamics of the bank's EBIT.

Consider a complete probability space $(\Omega, \mathcal{F}, \mathbb{P})$ equipped with an augmented filtration $\mathbb{F}:=$ $\left\{\mathcal{F}_{t}\right\}_{t \geq 0}$ generated by a Markov chain and a Brownian motion to be specified below. Here $\mathbb{P}$ denotes the real-world probability measure. Throughout this paper, the economy is categorized into $N$ states or regimes, indexed by a set of integers $\mathcal{N}:=\{1,2, \cdots, N\}$. The information about the effective economic state over time ${ }^{1}$, is carried by a vector $\delta(t)$ taking values from a set of $\mathbb{R}^{N}$-valued unit vectors $E=\left\{e_{1}, \ldots, e_{N}\right\}$, where $e_{j}=(0, \ldots, 1, \ldots, 0)^{\prime}$. The filtration generated by $\{\delta(t)\}_{t \geq 0}$ is denoted by $\left\{\mathcal{G}_{t}\right\}_{t \geq 0}$ and augmented in the usual way by $\left\{\mathcal{H}_{t}\right\}_{t \geq 0}$. $\mathcal{H}_{t}$ carries the information about the bank's EBIT and is such that $\mathcal{F}_{t}=\mathcal{G}_{t} \vee \mathcal{H}_{t}$. The generator of $\delta(t)$ is an $N \times N$ matrix $Q_{0}:=\left[q_{i, j}\right]_{i, j=1,2, \ldots, N}$, whose elements satisfy the following standard conditions:

$$
q_{i, j} \geq 0, \quad \forall i \neq j, \quad \text { and } \quad \sum_{j=1}^{N} q_{i, j}=0, \quad \forall i \in \mathcal{N} .
$$

Note that when $\Delta t$ is small, $q_{i, j} \Delta t$ is the approximation probability of a switch from state $i$ to state $j$, for $i \neq j$. The matrix of transition probabilities, denoted as $P(t, s)$, is given by

$$
P(t, s)=\exp \left(Q_{0}(s-t)\right), \quad s \geq t,
$$

and its elements, denoted as $p_{i, j}(t, s), i, j \in \mathcal{N}$, are such that

$$
p_{i, j}(t, s)=P\left(\delta(s)=e_{j} \mid \delta(t)=e_{i}\right), \quad i, j \in \mathcal{N},
$$

where $p_{i, j}(t, s)$ is the transition probability of a switch from state $i$ at time $t$ to state $j$ at time $s$. The probability of the chain being in state $i$ at time $t$, denoted by $p_{i}(t)$, depends upon the initial probabilities $p_{k}(0)$ at time $t=0$ and the transition probabilities $p_{k, i}(0, t)$, where $k=1,2, \ldots, N$, as follows:

$$
p_{i}(t)=P\left(\delta(t)=e_{i}\right)=\sum_{k=1}^{N} p_{k}(0) p_{k, i}(0, t), \quad \forall i \in \mathcal{N} .
$$

In Elliott et al. (1994), the following semi-martingale representation theorem for $\delta(t)$ is provided

$$
\delta(t)=\delta(0)+\int_{0}^{t} Q_{0}^{\prime} \delta(s) d s+M_{t}
$$

where $\left\{M_{t}\right\}_{t \geq 0}$ is an $\mathbb{R}^{N}$-valued, $(\mathbb{G}, \mathbb{P})$-martingale increment process.

Ammann and Genser (2005), Hackbarth et al. (2006) and Koziol and Lawrenz (2012) study an EBIT-based capital structure model. This work adopts the same approach and extends it to the case of a Markov-modulated geometric Brownian motion EBIT dynamics. Specifically, the bank's EBIT, also used as an approximation of the bank's cash-flow, is assumed to be $e^{X_{t}}$ at time $t$ and the dynamics of $\left\{X_{t}\right\}_{t \geq 0}$ under $\mathbb{P}$ is governed by the following Markov-modulated Brownian motion with drift:

$$
d X_{t}=\bar{\mu}_{t} d t+\sigma_{t} d W_{t}, \quad X_{0}=x_{0},
$$

\footnotetext{
${ }^{1}$ Notice that the economic regime is assumed observable. However, as explained in the last paragraph of section 6 , most of our results may be extended to hidden regimes.
} 
where $\left\{W_{t}\right\}_{t \geq 0}$ is an $(\mathbb{F}, \mathbb{P})$-standard Brownian motion. Here the drift and volatility parameters are modulated by the Markov chain. That is, $\bar{\mu}_{t}=\delta(t)^{\prime} \bar{\mu}$ and $\sigma_{t}=\delta(t)^{\prime} \sigma$, where $\bar{\mu}=\left(\bar{\mu}_{1}, \ldots, \bar{\mu}_{N}\right)^{\prime}$ and $\sigma=\left(\sigma_{1}, \ldots, \sigma_{N}\right)^{\prime}$ are the vectors of drifts and volatilities in all economic regimes. With a little abuse of notation, let $\sigma^{2}=\left(\sigma_{1}^{2}, \ldots, \sigma_{N}^{2}\right)^{\prime}$ denote the vector of squared volatilities in all economic regimes.

Macroeconomic conditions also influence the risk-free rate. As observed in Japan over the last decade, or in Europe recently, economic recessions can cause deflation and low interest rates, while economic booms can result in inflation and high interest rates. To integrate this feature in the modeling framework, the risk-free rate is assumed to be determined by the economic regime as $r_{t}=\delta(t)^{\prime} r$, where $r=\left(r_{1}, \ldots, r_{N}\right)^{\prime}$ denotes the vector of risk-free rates in all economic regimes.

The next proposition recalls an useful result established by Elliott and Siu (2013), which is used throughout this paper.

Proposition 2.1. Let $B(u)$ be an $N \times N$ diagonal matrix of $\phi(u)=\bar{\mu} u+\frac{1}{2} u^{2} \sigma^{2}$, i.e. $B(u)=$ $\operatorname{diag}(\phi(u))$. The Laplace transform of $X_{t}$ under $\mathbb{P}$ is given by:

$$
\mathbb{E}^{P}\left[e^{u X_{t}}\right]=e^{u x_{0}} \delta(0)^{\prime} \exp \left(\left(Q_{0}+B(u)\right) t\right) \mathbf{1},
$$

where 1 is a vector of ones and $\mathbb{E}^{P[\cdot]}$ denotes the expectation under $\mathbb{P}$.

Before introducing the capital structure, the remainder of this section focuses on the valuation of bank's asset. The totality of bank's cash-flow ${ }^{2}$ is generated by the asset, which is traded in financial markets. To avoid arbitrage opportunities, the price of the asset should be equal to the expected present value of the future net cash flow under a risk neutral measure $\mathbb{Q}$. However, as is known, the financial market with regime-switching is incomplete by nature and there exists more than one risk neutral measures. Under different criteria, different equivalent measures can be suggested. For example, the minimal entropy martingale measure and the variance-optimal martingale measure are constructed by minimizing the Kullback-Leibler distance, i.e. the relative entropy, and the $L^{2}$-norm, respectively. Although the selection of equivalent measures itself is an important research topic in finance, this paper will not discuss which criterion is better. Instead, the Esscher transformation method is adopted directly to select the risk neutral measure. The Esscher transform is a time-honored tool in actuarial science and has been promoted by Gerber and Shiu (1994) in option pricing. The merit of the risk neutral measure determined by the Esscher tranform is that it provides a general, transparent and unambiguous framework. As shown in Elliott et al. (2005), a regime-switching Esscher transform is defined by a so-called regime-switching Esscher parameter $\xi_{t}=\delta(t)^{\prime} \xi$, where $\xi=\left(\xi_{1}, \xi_{2}, \ldots, \xi_{N}\right)^{\prime}$. Specifically, the risk neutral measure $\mathbb{Q}$ is equivalent to $\mathbb{P}$ through the Radon Nykodym density as follows

$$
\left.\frac{d \mathbb{Q}}{d \mathbb{P}}\right|_{\mathcal{F}_{t}}=\frac{e^{\int_{0}^{t} \xi_{s} d X_{s}}}{\mathbb{E}^{P}\left[e^{\int_{0}^{t} \xi_{s} d X_{s}} \mid \mathcal{G}_{t}\right]}=e^{-\frac{1}{2} \int_{0}^{t} \xi_{s}^{2} \sigma_{s}^{2} d s+\int_{0}^{t} \xi_{s} \sigma_{s} d W_{s}} .
$$

Since $\xi$ and $\sigma$ are constant and hence bounded, the stochastic exponential on the right hand side of the above equation is an $(\mathbb{F}, \mathbb{P})$-martingale and then the equivalent measure $\mathbb{Q}$ is well defined. The method to infer the value of $\xi$ is explained at the end of this section. The next proposition gives the dynamics of $\left\{X_{t}\right\}_{t \geq 0}$ under $\mathbb{Q}$, where its drift is modified.

Proposition 2.2. The process $\left\{X_{t}\right\}_{t \geq 0}$ is governed by the following SDE under $\mathbb{Q}$

$$
d X_{t}=\mu_{t} d t+\sigma_{t} d W_{t}^{\mathbb{Q}}, \quad X_{0}=x_{0},
$$

\footnotetext{
${ }^{2}$ In the model, the EBIT is used as an estimate of the firm's cash-flow.
} 
where

$$
W_{t}^{\mathbb{Q}}=W_{t}-\int_{0}^{t} \xi_{s} \sigma_{s} d s, \quad \forall t \geq 0,
$$

is a standard Brownian motion under $\mathbb{Q}$. Here the drift of $X_{t}$ is equal to $\mu_{t}=\delta(t)^{\prime} \mu$ with the vector $\mu$ defined by

$$
\mu=\left(\bar{\mu}_{j}+\xi_{j} \sigma_{j}^{2}\right)_{j=1, \ldots, N}^{\prime} .
$$

Proof. From Girsanov's theorem, the process defined by (9) is a standard Brownian motion under $\mathbb{Q}$. Substituting (9) into (6) immediately gives the dynamics of $X_{t}$ under $\mathbb{Q}$ and its drift, i.e. (8) and (10).

At time $t$, the value of the bank's asset, denoted by $A_{t}$, is the expected present value of future net cash flow under the risk neutral measure $\mathbb{Q}$. If the tax rate is denoted by $\gamma, A_{t}$ is equal to the following expression

$$
A_{t}=\mathbb{E}\left[(1-\gamma) \int_{t}^{+\infty} e^{-\int_{t}^{s} r_{u} d u} e^{X_{s}} d s \mid \mathcal{F}_{t}\right] .
$$

Here and afterward $\mathbb{E}[\cdot]$ denotes the expectation under $\mathbb{Q}$. This value should be seen as the purchase price of assets under the bank's management. Its closed-form expression is detailed in the next proposition, which is proportional to the bank's current EBIT:

Proposition 2.3. The market values of the bank's asset $A_{t}$, is equal to:

$$
A_{t}=-(1-\gamma) e^{x_{t}}\left(\delta(t)^{\prime}\left(Q_{0}+B^{\xi}\right)^{-1} \mathbf{1}\right)
$$

where

$$
B^{\xi}=\operatorname{diag}\left[\left(\bar{\mu}_{j}+\xi_{j} \sigma_{j}^{2}+\frac{1}{2} \sigma_{j}^{2}-r_{j}\right)_{j=1, \ldots, N}^{\prime}\right]
$$

under conditions

$$
\bar{\mu}_{j}+\xi_{j} \sigma_{j}^{2}+\frac{1}{2} \sigma_{j}^{2}<r_{j}, \quad j=1, \ldots, N .
$$

Proof. These results are obtained by direct integration and using a variant of Proposition 2.1:

$$
\begin{aligned}
A_{t} & =(1-\gamma) e^{x_{t}} \int_{t}^{\infty} \mathbb{E}^{P}\left[e^{\int_{t}^{s}\left(\mu_{u}-r_{u}-\frac{1}{2} \xi_{u}^{2} \sigma_{u}^{2}\right) d u+\int_{t}^{s}\left(1+\xi_{u}\right) \sigma_{u} d W_{u}} \mid \mathcal{F}_{t}\right] d s \\
& =(1-\gamma) e^{x_{t}} \int_{t}^{\infty} \delta(t)^{\prime} \exp \left(\left(Q_{0}+B^{\xi}\right)(s-t)\right) \mathbf{1} d s \\
& =(1-\gamma) e^{x_{t}}\left[\delta(t)^{\prime}\left(Q_{0}+B^{\xi}\right)^{-1} \exp \left(\left(Q_{0}+B^{\xi}\right)(s-t)\right) \mathbf{1}\right]_{s=t}^{s=\infty} \\
& =-(1-\gamma) e^{x_{t}}\left(\delta(t)^{\prime}\left(Q_{0}+B^{\xi}\right)^{-1} \mathbf{1}\right) .
\end{aligned}
$$

If conditions given by (14) are violated, the asset value is infinite. Eq. (12) reveals that the asset value $A_{t}$ is not continuous. As it depends upon $\delta(t)$ directly, a change of economic regime causes a sudden jump in the asset value. The next proposition introduces additional conditions that $\xi$ fulfills to guarantee the absence of arbitrage. 
Proposition 2.4. Vector $\xi=\left(\xi_{1}, \xi_{2}, \ldots, \xi_{N}\right)$ defines a risk neutral measure if and only if it is the solution of the following system:

$$
r_{i}=\bar{\mu}_{i}+\xi_{i} \sigma_{i}^{2}+\frac{1}{2} \sigma_{i}^{2}+\sum_{j \neq i} q_{i, j}\left(\frac{e_{j}^{\prime}\left(Q_{0}+B^{\xi}\right)^{-1} \mathbf{1}}{e_{i}^{\prime}\left(Q_{0}+B^{\xi}\right)^{-1} \mathbf{1}}-1\right), \quad i=1, \ldots, N .
$$

Proof. Using Itô's lemma for semi-martingales leads to the following dynamics for the asset:

$$
d A_{t}=A_{t} d X_{t}+\frac{1}{2} A_{t}\left\langle d X_{t}, d X_{t}\right\rangle+\left(A_{t+}-A_{t}\right) d \delta(t)
$$

Then, if $\delta(t)=e_{i}$ and the asset value in this state is noted by $A_{t}^{(i)}$, the expectation of Eq. (16) is hence given by

$$
\mathbb{E}\left[d A_{t} \mid \mathcal{F}_{t}\right]=A_{t}^{(i)}\left(\mu_{i}+\frac{1}{2} \sigma_{i}^{2}\right) d t+\sum_{j \neq i} q_{i, j}\left(\frac{A_{t}^{(j)}}{A_{t}^{(i)}}-1\right) A_{t}^{(i)} d t,
$$

where the ratio $\frac{A_{t}^{(j)}}{A_{t}^{(i)}}$ is independent from time and equal to

$$
\frac{A_{t}^{(j)}}{A_{t}^{(i)}}=\frac{e_{j}^{\prime}\left(Q_{0}+B^{\xi}\right)^{-1} \mathbf{1}}{e_{i}^{\prime}\left(Q_{0}+B^{\xi}\right)^{-1} \mathbf{1}}
$$

Since expectation (17) under the risk neutral measure must be equal to the risk free rate in regime $i$, i.e. $\mathbb{E}\left[d A_{t} \mid \mathcal{F}_{t}\right]=r_{i} A_{t}^{(i)} d t$, system (15) immediately follows.

In numerical applications, the system of Eqs. (15) is solved numerically so as to infer $\xi$. The next section introduces different categories of liabilities, which are used to finance the purchase of the bank's asset. Note that all further developments are done under the risk neutral measure $\mathbb{Q}$.

\section{Bank's equity and liabilities}

Suppose that the bank is participating in financial markets to fulfill its financing needs through issuing deposits, straight bonds and CoCo bonds. Deposits and straight bonds are assumed to be fixed coupon consols, paying continuous coupons at the rates of $\pi_{1}^{d}$ and $\pi_{1}^{s d}$, respectively. The total charge of these consol bonds is denoted by $\pi_{1}=\pi_{1}^{d}+\pi_{1}^{s d}$. Deposits are insured in case of bankruptcy and the bank pays a fair deposit insurance premium in exchange, denoted as $D I_{t}$. In case of bankruptcy, assets owned by the bank are sold at a significant discount and used solely to repay holders of deposits and straight bonds. To enhance the solvency, the bank also issues CoCo bonds. Before conversion, these debts are similar to straight debts and pay a continuous coupon at the rate of $\pi_{2}$. In case of insolvency, they are converted into equity and the payment of coupons is terminated.

Under the assumption that the total earnings are distributed to shareholders, if $\gamma$ is the tax rate, a total dividend of $(1-\gamma)\left(e^{X_{t}}-\pi_{1}-\pi_{2}\right)$ is paid before the conversion of CoCo bonds. If CoCo bonds are swapped into equity, the total dividend distributed to all shareholders, including former CoCo bondholders, becomes $(1-\gamma)\left(e^{X_{t}}-\pi_{1}\right)$. The number of existing shares and potential new shares are denoted by $N_{S}$ and $N_{C}$, respectively. Then upon conversion, earnings allocated to former shareholders and new shareholders are thus $\frac{N_{S}}{N_{S}+N_{C}}(1-\gamma)\left(e^{X_{t}}-\pi_{1}\right)$ and $\frac{N_{C}}{N_{S}+N_{C}}(1-\gamma)\left(e^{X_{t}}-\pi_{1}\right)$, respectively. 
According to Basel II and III, insolvency is triggered when the Mc Donough ratio (Tier I and II core equity on Total Risk Weighted Assets) falls below 8\%. In this model, the event of financial distress is instead approached by a lower bound on the EBIT. The conversion of CoCo bonds to equity is triggered by the event that the EBIT falls below a threshold proportional to the sum of payments to all debtholders, i.e., $\theta\left(\pi_{1}+\pi_{2}\right)$, where $\theta$ is either chosen by the regulator or shareholders. Then the stopping time corresponding to the conversion is defined as follows:

$$
\tau_{1}=\inf \left\{t \geq 0: X_{t}<\ln \left(\theta\left(\pi_{1}+\pi_{2}\right)\right)\right\} .
$$

Once CoCo bonds have been swapped, the bank has no other tool to mitigate the risk of insolvency. The bank enters bankruptcy when the EBIT falls below the same regulatory threshold. After conversion, the default time is then defined by

$$
\tau_{2}=\inf \left\{t \geq 0: X_{t}<\ln \left(\theta \pi_{1}\right)\right\} .
$$

At any time $t$ before conversion, the market value of bank equity, gross of deposit insurance ${ }^{3}$, denoted by $S_{t}$, is the sum of two terms:

$$
S_{t}=\mathbb{E}\left[\int_{t}^{\tau_{1}} e^{-\int_{t}^{s} r_{u} d u}(1-\gamma)\left(e^{X_{s}}-\pi_{1}-\pi_{2}\right) d s+\frac{N_{S}}{N_{S}+N_{C}} e^{-\int_{t}^{\tau_{1}} r_{u} d u} S_{\tau_{1}} \mid \mathcal{F}_{t}\right], \quad t<\tau_{1},
$$

where the first term is the expected discounted value of future dividends till the conversion of CoCo bonds into equity, and the second term is the part of capital owned by the incumbent (existing) equityholders. Here $S_{\tau_{1}}$ is the total bank equity at the instant that CoCo bonds is swapped into new shares. At time $\tau_{1} \leq t \leq \tau_{2}$, this market value is the sum of discounted cash flows till default and the recovery value of bank's asset upon default:

$$
S_{t}=\mathbb{E}\left[\int_{t}^{\tau_{2}} e^{-\int_{t}^{s} r_{u} d u}(1-\gamma)\left(e^{X_{s}}-\pi_{1}\right) d s+(1-\lambda)(1-\gamma) \int_{\tau_{2}}^{\infty} e^{-\int_{t}^{s} r_{u} d u} e^{X_{s}} d s \mid \mathcal{F}_{t}\right],
$$

where $1-\lambda$ is the (constant) recovery rate of bank's assets, after liquidation, transferred to shareholders. In this framework, equity values per share before and after conversion are respectively given by $\frac{S_{t}}{N_{S}}$ if $t<\tau_{1}$ and $\frac{S_{t}}{N_{S}+N_{C}}$ if $\tau_{1} \leq t \leq \tau_{2}$.

Straight debts and deposits are both modeled as consol bonds and their market values are the expected discounted sum of future coupons, net of tax, and of recovered principals in case of bankruptcy. Under the assumption that the residual value is directly proportional to interests paid, their market values can be respectively represented as follow for $t \leq \tau_{2}$ :

$$
D_{t}^{1, s d}=\mathbb{E}\left[\int_{t}^{\tau_{2}} e^{-\int_{t}^{s} r_{u} d u}(1-\gamma) \pi_{1}^{s d} d s+\lambda \frac{\pi_{1}^{s d}}{\pi_{1}}(1-\gamma) \int_{\tau_{2}}^{\infty} e^{-\int_{t}^{s} r_{u} d u} e^{X_{s}} d s \mid \mathcal{F}_{t}\right],
$$

and

$$
D_{t}^{1, d}=\mathbb{E}\left[\int_{t}^{\tau_{2}} e^{-\int_{t}^{s} r_{u} d u}(1-\gamma) \pi_{1}^{d} d s+\lambda \frac{\pi_{1}^{d}}{\pi_{1}}(1-\gamma) \int_{\tau_{2}}^{\infty} e^{-\int_{t}^{s} r_{u} d u} e^{X_{s}} d s \mid \mathcal{F}_{t}\right] .
$$

The insurance purchased by the bank for hedging deposits is a put option on their market values (without tax benefit given that the insurance is triggered only in case of bankruptcy). The strike price of this option is the residual value of bank's assets allocated to depositors. Under the assumption that this residual value is directly proportional to interests paid, the fair insurance premium is equal to

$$
\begin{aligned}
D I_{t}= & \mathbb{E}\left[e ^ { - \int _ { t } ^ { \tau _ { 2 } } r _ { u } d u } \left\{\mathbb{E}\left[\pi_{1}^{d} \int_{\tau_{2}}^{\infty} e^{-\int_{\tau_{2}}^{s} r_{u} d u} d s \mid \mathcal{F}_{\tau_{2}}\right]\right.\right. \\
& \left.\left.-\mathbb{E}\left[\lambda \frac{\pi_{1}^{d}}{\pi_{1}}(1-\gamma) \int_{\tau_{2}}^{\infty} e^{-\int_{\tau_{2}}^{s} r_{u} d u} e^{X_{s}} d s \mid \mathcal{F}_{\tau_{2}}\right]\right\}_{+} \mid \mathcal{F}_{t}\right] .
\end{aligned}
$$

\footnotetext{
${ }^{3}$ The equity net of the deposit insurance is defined later as the equity value decreased by the premium for the deposit insurance.
} 
On the other hand, the market value of CoCo bonds is the sum of coupons paid till conversion and the capital after the swap of these bonds into equity:

$$
D_{t}^{2}=\mathbb{E}\left[\int_{t}^{\tau_{1}} e^{-\int_{t}^{s} r_{u} d u}(1-\gamma) \pi_{2} d s+\frac{N_{C}}{N_{S}+N_{C}} e^{-\int_{t}^{\tau_{1}} r_{u} d u} S_{\tau_{1}} \mid \mathcal{F}_{t}\right]
$$

After conversion, for any time $t \geq \tau_{1}$, former CoCo bondholders own $\frac{N_{C}}{N_{S}+N_{C}} S_{t}$ of equity. In addition, the firm's value is the sum of equity, deposits, straight bonds and CoCo bonds and minus the insurance premium. It is denoted by $V_{t}$ and has the following expression

$$
V_{t}=\mathbb{E}\left[(1-\gamma) \int_{t}^{\infty} e^{-\int_{t}^{s} r_{u} d u} e^{X_{t}} d s \mid \mathcal{F}_{t}\right]-D I_{t}
$$

It is interesting to note that the firm's value does not depend upon the conversion time of CoCo bonds into equity, but only depends on the default time, which determines the insurance premium.

All results can be extended to a stochastic recovery rate, independent from the economic regime. Fair values of liabilities and equity are still computable by propositions 5.1 to 6.2 that follows later. But in this case, the constant $\lambda$ has to be replaced by its average $\mathbb{E}(\lambda)$. This immediate extension is due to the fact that prices are expectations. The introduction of stochastic recovery rate has however an impact on the risk borne by debtholders. This is confirmed by Altman et al. (2002), who show that random recovery rates raise significantly the value at risk of debts but has a limited impact on provisions for credit losses. Notice that the recovery rate can eventually be linked to the economic regime. This does not present any technical difficulty but requires to replace in propositions 5.1 to 6.2 the product $\lambda \mathbf{1}$ by a vector $\Lambda$ that contains the expected recovery rates in each economic state.

\section{Properties of hitting times}

The solution of the first passage problem for $\left(\delta(t), X_{t}\right)$ across a constant level is related to the down-crossing ladder process $X_{t}:=\min _{0 \leq s \leq t} X_{s}$. Indeed, $X_{t}$ is also a Markov process on the same state space and its generator matrix is related to the matrix Wiener-Hopf factors $\left(Q_{+}, Q_{-}\right)$ of $\left(\delta(t), X_{t}\right)$.

Definition 4.1. A pair of irreducible $N \times N$ matrices $\left(Q_{r,+}, Q_{r,-}\right)$, i.e. matrices with nonnegative off-diagonal entries and non-positive row sums, is called the Wiener-Hopf factorization of $\left(\delta(t), X_{t}\right)$ associated with $r>0$ if the following second-order matrix-valued equations hold, i.e.

$$
\Xi\left(-Q_{r,+}\right)=\Xi\left(Q_{r,-}\right)=0
$$

where

$$
\Xi\left(Q_{r}\right):=\frac{1}{2} \Sigma^{2} Q_{r}^{2}+V Q_{r}+Q_{0}-R,
$$

with $\Sigma=\operatorname{diag}(\sigma), V=\operatorname{diag}(\mu)$ and $R=\operatorname{diag}(r)$.

Rogers (1994) proposes an algorithm to compute the matrix Wiener-Hopf factors by diagonalization. Jiang and Pistorius (2008) prove the uniqueness of the matrix Wiener-Hopf factors and establish an analytical expression for the Laplace transform of a hitting time in a more general jump-diffusion framework. The next proposition is a direct consequence of this last result and gives the relationship between the first passage time and the matrix Wiener-Hopf factors of $\left(\delta(t), X_{t}\right)$. 
Proposition 4.2. Consider the first passage time $\tau$ of $X_{t}$ below a constant level $\beta$,

$$
\tau=\inf \left\{t \geq 0: X_{t}<\beta\right\},
$$

and the contingent payoff $h(\tau)$ depends on the economic regime as $h(\tau)=\delta(\tau)^{\prime} h$, where $h=$ $\left(h_{1}, \ldots, h_{N}\right)^{\prime}$. The expected discounted value of the contingent payoff at time $\tau$ is equal to

$$
\mathbb{E}\left[e^{-\int_{0}^{\tau} r_{s} d s} h(\tau) \mid \mathcal{F}_{0}\right]=\delta(0)^{\prime} \exp \left(Q_{r,-}\left(x_{0}-\beta\right)\right) h,
$$

where $Q_{r,-}$ is the Wiener-Hopf factor determined by Eqs. (27)-(28).

The following algorithm is proposed by Rogers (1994) to derive the Wiener-Hopf factors from the second-order matrix-valued equations (27)-(28):

- Step 1: Calculate pairs of eigenvalues and eigenvectors $\left(\beta_{i, u}, v_{i}\right) \in\left(\mathbb{C}, \mathbb{C}^{N}\right)$, for $i=$ $1,2, \ldots, 2 N$, of

$$
\left(\begin{array}{cc}
0 & I_{0} \\
2 \Sigma^{-2}\left(R-Q_{0}\right) & -2 \Sigma^{-2} V
\end{array}\right)\left(\begin{array}{c}
v_{i} \\
w_{i}
\end{array}\right)=\left(\begin{array}{c}
v_{i} \\
w_{i}
\end{array}\right)
$$

where $I_{0}$ is an $N \times N$ matrix.

- Step 2: Sort pairs of eigenvalues and eigenvectors according to real parts of eigenvalues $\left(\operatorname{Re}\left(\beta_{1, u}\right) \leq \operatorname{Re}\left(\beta_{2, u}\right) \leq \ldots \leq \operatorname{Re}\left(\beta_{N, u}\right)\right)$.

- Step 3: Set $Z_{-}:=\left[v_{1}, \ldots, v_{N}\right]$ and $Z_{+}:=\left[v_{N+1}, \ldots, v_{2 N}\right]$, then $Q_{r,-}$ is

$$
Q_{-}=Z_{-} \operatorname{diag}\left(\beta_{1, u}, \ldots, \beta_{N, u}\right) Z_{+}^{-1},
$$

and its matrix exponential can be computed as

$$
\exp \left(Q_{-} x\right)=Z_{-} \operatorname{diag}\left(e^{\beta_{1, u} x}, \ldots, e^{\beta_{N, u} x}\right) Z_{+}^{-1} .
$$

Proposition 4.2 and the above algorithm will be used in the following sections to derive analytical expressions for the bank's equity and liabilities, including deposits, straight bonds and CoCo bonds as well as the insurance premium.

\section{$5 \quad$ Valuation of bank's equity and liabilities after conversion $\left(\tau_{1} \leq\right.$ $\left.t<\tau_{2}\right)$}

This section focuses on the period after the swap of CoCo bonds against equity. During this period, the bank is leveraged by deposits and straight debts and there remain only three claimants: depositors, debtholders and shareholders. However by definition, the market values of deposits, straight debts and insurance are independent from the conversion time of CoCo bonds. Then, their expressions also hold for any time before conversion.

Proposition 5.1. The market value of straight debts before default is equal to

$$
\begin{aligned}
D_{t}^{1, s d}= & (1-\gamma) \pi_{1}^{s d} \delta(t)^{\prime}\left[I_{0}-\exp \left(Q_{r,-}\left(x_{t}-\ln \left(\theta \pi_{1}\right)\right)\right)\right]\left(R-Q_{0}\right)^{-1} \mathbf{1} \\
& +(1-\gamma) \lambda \pi_{1}^{s d} \theta \delta(t)^{\prime} \exp \left(Q_{r,-}\left(x_{t}-\ln \left(\theta \pi_{1}\right)\right)\right)\left(R-B-Q_{0}\right)^{-1} \mathbf{1}, \quad t<\tau_{2},
\end{aligned}
$$

where $B=B(1)$ is defined in Proposition 2.1. 
Proof. By definition, the market price of straight debts is the sum of two terms:

$$
D_{t}^{1, s d}=(1-\gamma) \pi_{1}^{s d} \mathbb{E}\left[\int_{t}^{\tau_{2}} e^{-\int_{t}^{s} r_{u} d u} d s \mid \mathcal{F}_{t}\right]+(1-\gamma) \lambda \frac{\pi_{1}^{s d}}{\pi_{1}} \mathbb{E}\left[\int_{\tau_{2}}^{\infty} e^{-\int_{t}^{s} r_{u} d u} e^{X_{s}} d s \mid \mathcal{F}_{t}\right] .
$$

The first term of Eq. (31) can be decomposed into the difference of two expectations as follows

$$
\mathbb{E}\left[\int_{t}^{\tau_{2}} e^{-\int_{t}^{s} r_{u} d u} d s \mid \mathcal{F}_{t}\right]=\mathbb{E}\left[\int_{t}^{\infty} e^{-\int_{t}^{s} r_{u} d u} d s \mid \mathcal{F}_{t}\right]-\mathbb{E}\left[e^{-\int_{t}^{\tau_{2}} r_{u} d u} \int_{\tau_{2}}^{\infty} e^{-\int_{\tau_{2}}^{s} r_{u} d u} d s \mid \mathcal{F}_{t}\right],
$$

and from Proposition 2.1, the first expectation in the above expression can be calculated as follows

$$
\begin{aligned}
\mathbb{E}\left[\int_{t}^{\infty} e^{-\int_{t}^{s} r_{u} d u} d s \mid \mathcal{F}_{t}\right] & =\int_{t}^{\infty} \mathbb{E}\left[e^{-\int_{t}^{s} r_{u} d u} \mid \mathcal{F}_{t}\right] d s \\
& =\int_{t}^{\infty} \delta(t)^{\prime} \exp \left(\left(Q_{0}-R\right)(s-t)\right) \mathbf{1} d s \\
& =\left[\delta(t)^{\prime}\left(Q_{0}-R\right)^{-1} \exp \left(\left(Q_{0}-R\right)(s-t)\right) \mathbf{1}\right]_{s=t}^{s=\infty} \\
& =\delta(t)^{\prime}\left(R-Q_{0}\right)^{-1} \mathbf{1} .
\end{aligned}
$$

Using the tower property of conditional expectations to the second expectation on the right hand side of $(32)$ gives

$$
\begin{aligned}
\mathbb{E}\left[e^{-\int_{t}^{\tau_{2}} r_{u} d u} \int_{\tau_{2}}^{\infty} e^{-\int_{\tau_{2}}^{s} r_{u} d u} d s \mid \mathcal{F}_{t}\right] & =\mathbb{E}\left[e^{-\int_{t}^{\tau_{2}} r_{u} d u} \mathbb{E}\left[\int_{\tau_{2}}^{\infty} e^{-\int_{\tau_{2}}^{s} r_{u} d u} d s \mid \mathcal{F}_{\tau_{2}}\right] \mid \mathcal{F}_{t}\right] \\
& =\mathbb{E}\left[e^{-\int_{t}^{\tau_{2}} r_{u} d u} \int_{\tau_{2}}^{\infty} \delta\left(\tau_{2}\right)^{\prime} \exp \left(\left(Q_{0}-R\right)\left(s-\tau_{2}\right)\right) \mathbf{1} d s \mid \mathcal{F}_{t}\right] \\
& =\mathbb{E}\left[e^{-\int_{t}^{\tau_{2}} r_{u} d u}\left(\delta\left(\tau_{2}\right)^{\prime}\left(R-Q_{0}\right)^{-1} \mathbf{1}\right) \mid \mathcal{F}_{t}\right] \\
& =\delta(t)^{\prime} \exp \left(Q_{r,-}\left(x_{t}-\ln \left(\theta \pi_{1}\right)\right)\right)\left(R-Q_{0}\right)^{-1} \mathbf{1} .
\end{aligned}
$$

where the last equality follows from Proposition 4.2. Combining Eqs. (33) and (34) yields

$$
\mathbb{E}\left[\int_{t}^{\tau_{2}} e^{-\int_{t}^{s} r_{u} d u} d s \mid \mathcal{F}_{t}\right]=\delta(t)^{\prime}\left[I_{0}-\exp \left(Q_{r,-}\left(x_{t}-\ln \left(\theta \pi_{1}\right)\right)\right)\right]\left(R-Q_{0}\right)^{-1} \mathbf{1} .
$$

In the same vein, using the tower property of conditional expectations to the second term in (31) leads to

$$
\begin{aligned}
\mathbb{E}\left[\int_{\tau_{2}}^{\infty} e^{-\int_{t}^{s} r_{u} d u} e^{X_{s}} d s \mid \mathcal{F}_{t}\right] & =\mathbb{E}\left[\mathbb{E}\left[\int_{\tau_{2}}^{\infty} e^{-\int_{t}^{s} r_{u} d u} e^{X_{s}} d s \mid \mathcal{F}_{\tau_{2}}\right] \mid \mathcal{F}_{t}\right] \\
& =\mathbb{E}\left[e^{-\int_{t}^{\tau_{2}} r_{u} d u} e^{\ln \left(\theta \pi_{1}\right)} \int_{\tau_{2}}^{\infty} \mathbb{E}\left[e^{-\int_{\tau_{2}}^{s} r_{u} d u} e^{X_{t}-X_{\tau_{2}}} \mid \mathcal{F}_{\tau_{2}}\right] d s \mid \mathcal{F}_{t}\right] \\
& =\mathbb{E}\left[e^{-\int_{t}^{\tau_{2}} r_{u} d u} e^{\ln \left(\theta \pi_{1}\right)} \delta\left(\tau_{2}\right)^{\prime}\left(R-B-Q_{0}\right)^{-1} \mathbf{1} \mid \mathcal{F}_{t}\right] \\
& =e^{\ln \left(\theta \pi_{1}\right)} \delta(t)^{\prime} \exp \left(Q_{r,-}\left(x_{t}-\ln \left(\theta \pi_{1}\right)\right)\right)\left(R-B-Q_{0}\right)^{-1} \mathbf{1} \\
& =\theta \pi_{1} \delta(t)^{\prime} \exp \left(Q_{r,-}\left(x_{t}-\ln \left(\theta \pi_{1}\right)\right)\right)\left(R-B-Q_{0}\right)^{-1} \mathbf{1} .
\end{aligned}
$$

Combining (35) and (36) completes the proof.

The fair consol interest payment $\pi_{1}^{s d}$ should be determined at the issuance of straight debts, such that the market value of straight debts is equal to the amount brought by bondholders. This ensures the absence of arbitrage. However as shown by Eq. (30), this fair price is directly related to the total interest $\pi_{1}$ paid to depositors and debtholders, and then to the whole capital structure of the bank. This point will be further discussed in Section 8.

The next proposition introduces an analytical expression for price of the deposits insurance. 
Proposition 5.2. The value of the fair insurance premium before default is equal to

$$
D I_{t}=\delta(t)^{\prime} \exp \left(Q_{r,-}\left(x_{t}-\ln \left(\theta \pi_{1}\right)\right)\right) c, \quad t<\tau_{2},
$$

where $c=\left(c_{1}, c_{2}, \ldots, c_{N}\right)^{\prime}$ is the vector value of claims covered by the deposits insurance in all economic regimes with

$$
c_{i}=\left(\pi_{1}^{d} e_{i}^{\prime}\left(R-Q_{0}\right)^{-1} \mathbf{1}-\lambda(1-\gamma) \pi_{1}^{d} \theta e_{i}^{\prime}\left(R-B-Q_{0}\right)^{-1} \mathbf{1}\right)_{+}
$$

for $i=1, \ldots, N$.

Proof. As proved in Proposition 5.1, the market value of deposits when the default event occurs is such that

$$
\mathbb{E}\left[\pi_{1}^{d} \int_{\tau_{2}}^{\infty} e^{-\int_{\tau_{2}}^{s} r_{u} d u} d s \mid \mathcal{F}_{\tau_{2}}\right]=\pi_{1}^{d} \delta\left(\tau_{2}\right)^{\prime}\left(R-Q_{0}\right)^{-1} \mathbf{1}
$$

and the market value of assets sold is equal to

$$
\mathbb{E}\left[\int_{\tau_{2}}^{\infty} e^{-\int_{\tau_{2}}^{s} r_{u} d u} e^{X_{s}} d s \mid \mathcal{F}_{\tau_{2}}\right]=e^{\ln \left(\theta \pi_{1}\right)} \delta\left(\tau_{2}\right)^{\prime}\left(R-B-Q_{0}\right)^{-1} \mathbf{1}
$$

Combining expressions (39) and (40) gives the expressions for $c_{i}$. Then a direct application of Proposition 4.2 gives the fair price of the insurance.

In this paper, deposits are like consol bonds except that they are hedged by an insurance contract. As stated in the next proposition, their price has almost the same expression as straight debts. Given that their value is closely related to $\pi_{1}$, the fair interest paid to depositors is then directly influenced by the size of straight debts. On the other hand, interests paid to depositors should be smaller than those paid to debtholders, because the deposits insurance reduces their exposure to bankruptcy. The relationships between the fair deposits rate, volume of straight debts and insurance fee will be developed in Section 8.

Proposition 5.3. The market value of deposit before default is equal to

$$
\begin{aligned}
D_{t}^{1, d}= & (1-\gamma) \pi_{1}^{d} \delta(t)^{\prime}\left[I_{0}-\exp \left(Q_{r,-}\left(x_{t}-\ln \left(\theta \pi_{1}\right)\right)\right)\right]\left(R-Q_{0}\right)^{-1} \mathbf{1} \\
& +(1-\gamma) \lambda \pi_{1}^{d} \theta \delta(t)^{\prime} \exp \left(Q_{r,-}\left(x_{t}-\ln \left(\theta \pi_{1}\right)\right)\right)\left(R-B-Q_{0}\right)^{-1} \mathbf{1}, \quad t<\tau_{2},
\end{aligned}
$$

where $B=B(1)$ is defined in Proposition 2.1.

The proof of Proposition 5.3 is the same as that of Proposition 5.1. Contrary to deposits, straight debts or insurance premium, the expression for the market value of equity differs before and after conversion of CoCo bonds. After conversion, former shareholders are diluted and the total equity value is the sum of all expected discounted dividends.

Proposition 5.4. Given that $X_{t}=x_{t}$, the equity value $S_{t}$ after conversion and gross of deposit insurance is equal to

$$
\begin{aligned}
S_{t}= & (1-\gamma)\left[e^{x_{t}} \delta(t)^{\prime} I_{0}-\lambda \theta \pi_{1} \delta(t)^{\prime} \exp \left(Q_{r,-}\left(x_{t}-\ln \left(\theta \pi_{1}\right)\right)\right)\right]\left(R-B-Q_{0}\right)^{-1} \mathbf{1} \\
& -(1-\gamma) \pi_{1} \delta(t)^{\prime}\left[I_{0}-\exp \left(Q_{r,-}\left(x_{t}-\ln \left(\theta \pi_{1}\right)\right)\right)\right]\left(R-Q_{0}\right)^{-1} \mathbf{1}, \quad \tau_{1} \leq t<\tau_{2},
\end{aligned}
$$

where $B=B(1)$ is defined in Proposition 2.1. 
Proof. By definition, the equity value can be decomposed as follows

$$
\begin{aligned}
S_{t}= & (1-\gamma) \mathbb{E}\left[\int_{t}^{\infty} e^{-\int_{t}^{s} r_{u} d u} e^{X_{s}} d s \mid \mathcal{F}_{t}\right]-\lambda(1-\gamma) \mathbb{E}\left[\int_{\tau_{2}}^{\infty} e^{-\int_{t}^{s} r_{u} d u} e^{X_{s}} d s \mid \mathcal{F}_{t}\right] \\
& -\pi_{1} \mathbb{E}\left[\int_{t}^{\tau_{2}} e^{-\int_{t}^{s} r_{u} d u} d s \mid \mathcal{F}_{t}\right] .
\end{aligned}
$$

The first expectation in Eq. (43) can be derived as

$$
\begin{aligned}
\mathbb{E}\left[\int_{t}^{\infty} e^{-\int_{t}^{s} r_{u} d u} e^{X_{s}} d s \mid \mathcal{F}_{t}\right] & =\int_{t}^{\infty} \mathbb{E}\left[e^{-\int_{t}^{s} r_{u} d u} e^{X_{s}} \mid \mathcal{F}_{t}\right] d s \\
& =\int_{t}^{\infty} e^{x_{t}} \delta(t)^{\prime} \exp \left(\left(Q_{0}+B-R\right)(s-t)\right) \mathbf{1} d s \\
& =e^{x_{t}} \delta(t)^{\prime}\left(R-B-Q_{0}\right)^{-1} \mathbf{1} .
\end{aligned}
$$

The second and the third expectations in Eq. (43) can be derived as Eqs. (36) and (32) in Proposition 5.1. Combining them completes the proof.

After the swap of CoCo bonds into equity, the firm's value is the sum of equity, straight debts and deposits, minus the insurance premium (respectively provided by Eqs. (30), (37), (41) and (42)). A direct calculation leads to the following corollary.

Corollary 5.5. The firm's value $V_{t}=S_{t}+D_{t}^{1, s d}+D_{t}^{1, d}-D I_{t}$ after conversion and before default is given by

$$
\begin{aligned}
V_{t} & =A_{t}-D I_{t} \\
& =(1-\gamma) e^{x_{t}} \delta(t)^{\prime} I_{0}\left(R-B-Q_{0}\right)^{-1} \mathbf{1}-\delta(t)^{\prime} \exp \left(Q_{r,-}\left(x_{t}-\ln \left(\theta \pi_{1}\right)\right)\right) c, \quad \tau_{1} \leq t<\tau_{2} .
\end{aligned}
$$

\section{Value of CoCo bonds and equity before conversion $\left(t<\tau_{1}\right)$}

Before conversion, there are four claimants: shareholders, contingent capital holders, straight debtholders and depositors. Deposits and straight debts are independent of conversion and their market values can be calculated using the same formulas given in Propositions 5.1 and 5.2. The value of CoCo bonds, as shown in the next proposition, is the sum of two terms: one related to coupons paid till conversion and the other related to swapped equity in case of insolvency.

Proposition 6.1. The market value of CoCo bonds before conversion is given by

$$
\begin{aligned}
& D_{t}^{2}=(1-\gamma) \pi_{2} \delta(t)^{\prime}\left[I_{0}-\exp \left(Q_{r,-}\left(x_{t}-\ln \left(\theta\left(\pi_{1}+\pi_{2}\right)\right)\right)\right)\right]\left(R-Q_{0}\right)^{-1} \mathbf{1} \\
& \quad+\frac{N_{C}}{N_{S}+N_{C}} \delta(t)^{\prime} \exp \left(Q_{r,-}\left(x_{t}-\ln \left(\theta\left(\pi_{1}+\pi_{2}\right)\right)\right)\right) S_{C}, \quad t<\tau_{1},
\end{aligned}
$$

where $S_{C}$ is the vector of equity value after conversion of CoCo bonds into equity for all economic regimes:

$$
\begin{aligned}
S_{C}= & (1-\gamma)\left[\theta\left(\pi_{1}+\pi_{2}\right) I_{0}-\lambda \theta \pi_{1} \exp \left(Q_{r,-} \ln \left(1+\frac{\pi_{2}}{\pi_{1}}\right)\right)\right]\left(R-B-Q_{0}\right)^{-1} \mathbf{1} \\
& -(1-\gamma) \pi_{1}\left[I_{0}-\exp \left(Q_{r,-} \ln \left(1+\frac{\pi_{2}}{\pi_{1}}\right)\right)\right]\left(R-Q_{0}\right)^{-1} \mathbf{1} .
\end{aligned}
$$

Proof. By definition, the market value of CoCo bonds can be decomposed as follows:

$$
D_{t}^{2}=(1-\gamma) \pi_{2} \mathbb{E}\left[\int_{t}^{\tau_{1}} e^{-\int_{t}^{s} r_{u} d u} d s \mid \mathcal{F}_{t}\right]+\frac{N_{C}}{N_{S}+N_{C}} \mathbb{E}\left[e^{-\int_{t}^{\tau_{1}} r_{u} d u} S_{\tau_{1}} \mid \mathcal{F}_{t}\right]
$$


An analytical expression for the first term of Eq. (47) can be derived as Eq. (35) in the proof of Proposition 5.1. At time $\tau_{1}, x_{\tau_{1}}=\ln \left(\theta\left(\pi_{1}+\pi_{2}\right)\right)$ and $S_{\tau_{1}}$ is just a function of the state variable such that

$$
\begin{aligned}
S_{\tau_{1}} & =(1-\gamma)\left[\theta\left(\pi_{1}+\pi_{2}\right) \delta\left(\tau_{1}\right)^{\prime} I_{0}-\lambda \theta \pi_{1} \delta\left(\tau_{1}\right)^{\prime} \exp \left(Q_{r,-} \ln \left(1+\frac{\pi_{2}}{\pi_{1}}\right)\right)\right]\left(R-B-Q_{0}\right)^{-1} \mathbf{1} \\
& -(1-\gamma) \pi_{1} \delta\left(\tau_{1}\right)^{\prime}\left[I_{0}-\exp \left(Q_{r,-} \ln \left(1+\frac{\pi_{2}}{\pi_{1}}\right)\right)\right]\left(R-Q_{0}\right)^{-1} \mathbf{1}
\end{aligned}
$$

According to Proposition 4.2, the second expectation in Eq. (47) can thus be developed as follows:

$$
\mathbb{E}\left[e^{-\int_{t}^{\tau_{1}} r_{u} d u} S_{\tau_{1}} \mid \mathcal{F}_{t}\right]=\delta(t)^{\prime} \exp \left(Q_{r,-}\left(x_{t}-\ln \left(\theta\left(\pi_{1}+\pi_{2}\right)\right)\right)\right) S_{C} .
$$

The fair CoCo interest $\pi_{2}$ should be determined at the issuance of convertible debts, such that their market value is equal to the amount brought by CoCo bondholders to exclude any arbitrage opportunity. But as shown by Eq. (45), this fair rate is directly related to interests paid to holders of other liabilities. This interdependence is illustrated in Section 8. Using a similar approach as for CoCo bonds leads to a closed-form formula for the equity before conversion:

Proposition 6.2. The market value of the equity before conversion is given by

$$
\begin{aligned}
S_{t}= & (1-\gamma)\left[e^{x_{t}} \delta(t)^{\prime}-\theta\left(\pi_{1}+\pi_{2}\right) \delta(t)^{\prime} \exp \left(Q_{r,-}\left(x_{t}-\ln \left(\theta\left(\pi_{1}+\pi_{2}\right)\right)\right)\right)\right]\left(R-B-Q_{0}\right)^{-1} \mathbf{1} \\
& -(1-\gamma)\left(\pi_{1}+\pi_{2}\right) \delta(t)^{\prime}\left[I_{0}-\exp \left(Q_{r,-}\left(x_{t}-\ln \left(\theta\left(\pi_{1}+\pi_{2}\right)\right)\right)\right)\right]\left(R-Q_{0}\right)^{-1} \mathbf{1} \\
& +\frac{N_{S}}{N_{S}+N_{C}} \delta(t)^{\prime} \exp \left(Q_{r,-}\left(x_{t}-\ln \left(\theta\left(\pi_{1}+\pi_{2}\right)\right)\right) S_{C}, \quad t<\tau_{1},\right.
\end{aligned}
$$

where $S_{C}$ is defined by equation (46).

Proof. Remember that at any time $t<\tau_{1}, S_{t}$ is equal to the following sum:

$$
\begin{aligned}
S_{t}= & (1-\gamma) \mathbb{E}\left[\int_{t}^{\tau_{1}} e^{-\int_{t}^{s} r_{u} d u} e^{X_{t}} d s \mid \mathcal{F}_{t}\right]-(1-\gamma) \mathbb{E}\left[\int_{t}^{\tau_{1}} e^{-\int_{t}^{s} r_{u} d u}\left(\pi_{1}+\pi_{2}\right) d s \mid \mathcal{F}_{t}\right] \\
& +\frac{N_{S}}{N_{S}+N_{C}} \mathbb{E}\left[e^{-\int_{t}^{\tau_{1}} r_{u} d u} S_{\tau_{1}} \mid \mathcal{F}_{t}\right] .
\end{aligned}
$$

As shown in the proof of Proposition 5.4, the expected sums of the discounted EBIT and discounted coupons are respectively given by the following two equations

$$
\begin{aligned}
\mathbb{E}\left[\int_{t}^{\tau_{1}} e^{-\int_{t}^{s} r_{u} d u} e^{X_{t}} d s \mid \mathcal{F}_{t}\right]= & {\left[e^{x_{t}} \delta(t)^{\prime} I_{0}-\theta\left(\pi_{1}+\pi_{2}\right) \delta(t)^{\prime} \exp \left(Q_{r,-}\left(x_{t}-\ln \left(\theta\left(\pi_{1}+\pi_{2}\right)\right)\right)\right)\right] } \\
& \times\left(R-Q_{0}-B\right)^{-1} \mathbf{1},
\end{aligned}
$$

and

$$
\begin{aligned}
\mathbb{E}\left[\int_{t}^{\tau_{1}} e^{-\int_{t}^{s} r_{u} d u}\left(\pi_{1}+\pi_{2}\right) d s \mid \mathcal{F}_{t}\right]= & \left(\pi_{1}+\pi_{2}\right) \delta(t)^{\prime} \\
& \times\left[I_{0}-\exp \left(Q_{r,-}\left(x_{t}-\ln \left(\theta\left(\pi_{1}+\pi_{2}\right)\right)\right)\right)\right]\left(R-Q_{0}\right)^{-1} \mathbf{1} .
\end{aligned}
$$

Combining the above two equations with Eqs. (48) and (50) leads to the desired result. 
The firm's value $V_{t}$ is the sum of Eqs. (30), (41), (45) and (49), minus the insurance expressed by (37), i.e. $V_{t}=S_{t}^{1}+D_{t}^{2}+D_{t}^{1, d}+D_{t}^{1, s d}-D I_{t}$. It is easy to check that the expression of the firm's value for any time before conversion is equal to that after conversion and before default. That is,

$$
\begin{aligned}
V_{t}= & A_{t}-D I_{t} \\
= & (1-\gamma) e^{x_{t}} \delta(t)^{\prime} I_{0}\left(R-B-Q_{0}\right)^{-1} \mathbf{1} \\
& -\delta(t)^{\prime} \exp \left(Q_{r,-}\left(x_{t}-\ln \left(\theta \pi_{1}\right)\right)\right) c, \quad t<\tau_{1} .
\end{aligned}
$$

Remark: in this work, the Markov chain defining the economic regime is observable. The filtration $\mathcal{F}$ is then the augmentation of $\mathcal{G}$, the filtration of $\delta(t)$, and of $\mathcal{H}$, the filtration of the EBIT process. The main purpose of this assumption is to alleviate the presentation of mathematical developments. In numerical illustrations, the current economic regime can be set for this reason to the most likely one, filtered by the Hamilton algorithm (1989). However our results are extendable to the case of a hidden Markov chain. In this case, fair values of assets, liabilities and equity are equal to the expectation of their equivalents on the enlarged filtration, conditioned by the reduced filtration $\mathcal{H}$. In practice, this expectation is simply the sum of fair values in each regime, weighted by the probability of presence in this regime. For example, let us momentarily denote by $S_{t}^{\delta(t)}$ the equity value if the economy is in the regime $\delta(t)$, as defined in proposition 6.2. The equity value whether $\delta(t)$ is not visible is equal to the sum:

$$
S_{t}=\mathbb{E}\left(S_{t}^{\delta(t)} \mid \mathcal{H}_{t}\right)=\sum_{j=1}^{N} p_{j}(t) S_{t}^{e_{j}}
$$

The probabilities of presence are again computable with the Hamilton filter, applied directly to the earning process or to a related quantity. The next section develops some interesting indicators for risk management.

\section{$7 \quad$ Expected times and probabilities before conversion and ruin}

Introducing CoCo bonds to a bank's balance sheet is an efficient way to mitigate the risk of bankruptcy. However, former major shareholders bear the risk of being diluted in case of insolvency when CoCo bonds are swapped into equity, and losing control of the firm. This section introduces several indicators that can be used to monitor the risk of bankruptcy or dilution. The first useful tool is the expected lifetime before conversion or bankruptcy. The second tool is the probability of ruin or conversion. Both expected lifetime and probability are retrieved numerically by deriving the characteristic functions of conversion and bankruptcy times. The framework is applied here under the pricing measure $\mathbb{Q}$, but it is also applicable under the real world probability measure $\mathbb{P}$. In the latter case, it suffices to replace the parameters of $X_{t}$ by those observed under $\mathbb{P}$. If $\beta_{1}$ and $\beta_{2}$ respectively denotes $\theta\left(\pi_{1}+\pi_{2}\right)$ and $\theta \pi_{1}$, the characteristic functions of $\tau_{k}$ for $k=1,2$ are defined by

$$
\begin{aligned}
\varphi_{k}(u) & =\mathbb{E}\left(e^{i u \tau_{k}} \mid \mathcal{F}_{0}\right) \\
& =\delta(0)^{\prime} \exp \left(Q_{(-i u),-}\left(x_{0}-\ln \left(\beta_{k}\right)\right)\right) \mathbf{1}, \quad k=1,2,
\end{aligned}
$$

where $Q_{(-i u),-}$ are solutions of the following second-order matrix-valued equations

$$
\frac{1}{2} \Sigma^{2} Q_{(-i u),-}^{2}+V Q_{(-i u)}+Q_{0}+i u I_{0}=0, \quad i=1,2, \cdots, N .
$$

Then, the $n$-th moments of $\tau_{k}$ for $k=1,2$ are given by

$$
\mathbb{E}\left(\tau_{k}^{n} \mid \mathcal{F}_{0}\right)=\left.(-i)^{n} \frac{\partial^{n}}{\partial u^{n}} \varphi_{k}(u)\right|_{u=0}, \quad k=1,2 .
$$


Since there is no closed-form expression for $\left.\frac{\partial^{n}}{\partial u^{n}} \varphi(i u)\right|_{u=0}$, the first and second order derivatives are computed numerically. The capital structure also determines probabilities of default and conversion of CoCo bonds into equity over a certain time horizon. These probabilities can be retrieved from the Laplace transform of the hitting time $\tau_{k}$, for $k=1,2$. By definition, for a given constant $\alpha$, the Laplace transform of $\tau_{k}$ is such that

$$
\begin{aligned}
\mathbb{E}\left(e^{-\alpha \tau_{k}} \mid \mathcal{F}_{0}\right) & =\delta(0)^{\prime} \exp \left(Q_{(\alpha),-}\left(x_{0}-\ln \left(\beta_{k}\right)\right)\right) \mathbf{1} \\
& =\alpha \int_{0}^{+\infty} e^{-\alpha s} P\left(\tau_{k} \leq s \mid \mathcal{F}_{0}\right) d s \\
& =\alpha \mathcal{L}_{\alpha}\left(P\left(\tau_{k} \leq s \mid \mathcal{F}_{0}\right)\right), \quad k=1,2,
\end{aligned}
$$

where $\mathcal{L}_{\alpha}$ is the Laplace operator. The probability of conversion or default is then obtained by inverting the Laplace transform as follows

$$
\begin{aligned}
P\left(\tau_{k} \leq s \mid \mathcal{F}_{0}\right) & =\mathcal{L}_{\alpha}^{-1}\left(\frac{1}{\alpha} \mathbb{E}\left[e^{-\alpha \tau_{k}} \mid \mathcal{F}_{0}\right]\right) \\
& =\frac{1}{2 \pi i} \lim _{T \rightarrow \infty} \int_{\gamma-i T}^{\gamma+i T} e^{\alpha s} \frac{1}{\alpha} \mathbb{E}\left(e^{-\alpha \tau_{k}} \mid \mathcal{F}_{0}\right) d \alpha
\end{aligned}
$$

where $\gamma$ is greater than the real part of all singularities of $\mathbb{E}\left(e^{-\alpha \tau_{k}} \mid \mathcal{F}_{0}\right)$. In numerical applications, this transform is inverted using Talbot's method such as detailed in Abate and Whitt (2006).

\section{Fair pricing}

Table 1 presents the economic balance sheet at time $t$, in which market values of all items are accounted. As the premium of the deposit insurance is an immediate expense for the bank, it is deducted from both asset and equity. The equity, net of deposits insurance, is denoted by $S_{t}^{I}=S_{t}-D I_{t}$. The remainder of this section introduces the conditions that ensure no cross-subsidization among deposits, straight debts and CoCo bonds.

Table 1: Economic balance sheet of the financial institution at time $t$

\begin{tabular}{|c|c|c|c|}
\hline & Assets & & Equity and liabilities \\
\hline \multirow{3}{*}{ Assets, } & & Equity, net of insurance & $S_{t}^{I}=S_{t}-D I_{t}$ \\
& \multirow{2}{*}{$A_{t}-D I_{t}$} & CoCo bonds & $D_{t}^{2}$ \\
& & Straight debts & $D_{t}^{1, s d}$ \\
& & Deposits & $D_{t}^{1, d}$ \\
\hline Firm Value & $V_{t}=A_{t}-D I_{t}$ & Firm Value & $V_{t}=S_{t}+D_{t}^{2}+D_{t}^{1, s d}+D_{t}^{1, d}-D I_{t}$ \\
\hline
\end{tabular}

In order to clearly emphasize the link between the capital structure and costs of liabilities, it is assumed that the bank is founded at time $t=0$. The amounts of cash invested by equityholders, CoCo-bondholders, straight-bondholders or depositors are respectively denoted by $E_{0}$, $C C D_{0}, S D_{0}$ and $C D_{0}$. The total funds raised by the bank is invested in an asset such that $A_{0}=E_{0}+C C D_{0}+S D_{0}+C D_{0}$ and the dynamics of cash-flows $X_{t}$ paid by this asset is such that relationship (11) is satisfied. To exclude arbitrage opportunities, coupons paid to the three types of debts must guarantee that the market values of equity and liabilities are equal to the cash invested exactly:

$$
\begin{cases}E_{0} & =S_{0}^{I}=S_{0}-D I_{0} \\ C C D_{0} & =D_{0}^{2} \\ S D_{0} & =D_{0}^{1, s d} \\ C D_{0} & =D_{0}^{1, d}+D I_{0} .\end{cases}
$$


The last equation of system (57) guarantees that there is no subsidization of deposits insurance by equity holders or by CoCo bondholders and straight bondholders. If such an equation is satisfied, the insurance premium is only financed by deposits. On the other hand, the firm's value is equal to $F_{0}=A_{0}-D I_{0}$. Assume that the recovery rate $\lambda$, the default trigger $\theta$ and numbers of stocks $N_{S}$ or $N_{C}$ are known. The next corollary introduces a system of equations to determine the fair coupons $\pi_{1}^{d}$ and $\pi_{1}^{s d}$.

Corollary 8.1. If straight bondholders and depositors respectively bring $C S D_{0}$ and $C D_{0}$ in cash, the fair coupons are solutions of the following nonlinear system of equations:

$$
\left\{\begin{aligned}
\pi_{1}^{s d}= & \frac{C S D_{0}}{(1-\gamma)}\left[\delta(0)^{\prime}\left[I_{0}-\exp \left(Q_{r,-}\left(x_{0}-\ln \left(\theta \pi_{1}\right)\right)\right)\right]\left(R-Q_{0}\right)^{-1} \mathbf{1}\right. \\
& \left.+\lambda \theta \delta(0)^{\prime} \exp \left(Q_{r,-}\left(x_{0}-\ln \left(\theta \pi_{1}\right)\right)\right)\left(R-B-Q_{0}\right)^{-1} \mathbf{1}\right]^{-1}, \\
\pi_{1}^{d} & =\frac{\left(C D_{0}-D I_{0}\left(\pi_{1}^{d}\right)\right)}{(1-\gamma)}\left[\delta(0)^{\prime}\left[I_{0}-\exp \left(Q_{r,-}\left(x_{0}-\ln \left(\theta \pi_{1}\right)\right)\right)\right]\left(R-Q_{0}\right)^{-1} \mathbf{1}\right. \\
& \left.\lambda \theta \delta(0)^{\prime} \exp \left(Q_{r,-}\left(x_{0}-\ln \left(\theta \pi_{1}\right)\right)\right)\left(R-B-Q_{0}\right)^{-1} \mathbf{1}\right],
\end{aligned}\right.
$$

where $D I_{0}\left(\pi_{1}^{d}\right)$ is the value of the deposit insurance calculated by equation (37) and $\pi_{1}=\pi_{1}^{s d}+\pi_{1}^{d}$.

From the above corollary, the fair yields for depositors and bondholders are thus $y_{1}^{s d}=\frac{\pi_{1}^{s d}}{C S D_{0}}$ and $y_{1}^{d}=\frac{\pi_{1}^{d}}{C D_{0}}$. By construction, when $\pi_{1}^{s d}$ and $\pi_{1}^{d}$ satisfy system (58), $S D_{0}=D_{0}^{1, s d}$ and $C D_{0}=D_{0}^{1, d}+D I_{0}$. The money invested by depositors is then equal to the sum of market values of deposits and deposit insurance fee. System (58) is easily solved numerically in an example presented in the next section. The next result presents the equation that the fair coupon $\pi_{2}$ has to satisfy.

Corollary 8.2. If CoCo bondholders invest an amount $C C D_{0}$, the fair coupon is the solution of the following nonlinear equation:

$$
\begin{aligned}
\pi_{2}= & \frac{C C D_{0}}{(1-\gamma)}\left[\delta(t)^{\prime}\left[I_{0}-\exp \left(Q_{r,-}\left(x_{t}-\ln \left(\theta\left(\pi_{1}+\pi_{2}\right)\right)\right)\right)\right]\left(R-Q_{0}\right)^{-1} \mathbf{1}\right. \\
& \left.+\frac{N_{C}}{N_{S}+N_{C}} \delta(t)^{\prime} \exp \left(Q_{r,-}\left(x_{t}-\ln \left(\theta\left(\pi_{1}+\pi_{2}\right)\right)\right)\right) S_{C}\left(\pi_{2}\right)\right]
\end{aligned}
$$

where $S_{C}\left(\pi_{2}\right)$ is provided by equation (46).

From the above corollary, the fair yield of CoCo bonds is then $y_{2}=\frac{\pi_{2}}{C C D_{0}}$, which ensures $C C D_{0}=D_{0}^{2}$. Once that $\pi_{1}^{s d}, \pi_{1}^{d}$ and $\pi_{2}$ satisfy equations (58) and (59), it is easy to check that $E_{0}=S_{0}^{I}$.

\section{Numerical illustration}

Earnings are disclosed at most quarterly and the lack of data prevents using directly the accounting information to fit $X_{t}$ to real time series. Instead, practitioners consider that the daily quoted stock market value is close to a multiple of EBIT. It is thus reasonable to assume that earnings and stock prices are governed by the same dynamics, at least for calibration purposes. Then, based on daily stock quotes of a French bank, Société Générale, a regime-switching process is calibrated by a standard filtering procedure (Hamilton (1989)) and serves later as reference dynamics for $X_{t}$. The period considered for the calibration ranges from $2 / 1 / 2001$ to $10 / 3 / 2014$ (with 3431 observations).

Gatumel and Ielpo (2011) and Guidolin and Timmermann (2007) find that two regimes are not enough to capture asset dynamics for multiple securities. Their empirical results point out that between two and five regimes are required to capture the features of each asset's 
distribution. Based on this observation, models with two to five regimes are tested and their loglikelihoods, AIC and BIC are presented in Table 2. These statistics show that a model with four states achieves the best fit. Table 3 presents drifts and volatilities of stocks return on the annual basis. The matrix of transition probabilities is reported in Table 4. As discussed in Guidolin and Timmermann (2007), each state of $\delta(t)$ corresponds to an economic cycle. Table 3 shows that drifts decrease while volatilities increase from State 1 to State 4 . So States 1 and 2 are respectively characterized by bull and slow-growth markets, whereas States 3 and 4 are respectively identified as slowing down markets and market crashes.

Table 5 shows the average of 12 months Libor rates, observed in each economic regime. It also presents the vector $\xi$ defining the risk neutral measure $\mathbb{Q}$, which is the solution of the system of equations (15). The drifts of $X_{t}$ under the risk neutral measure $\mathbb{Q}$ are obtained from relationship (10). Since $\mu_{1}$ does not satisfy condition (14), the value of $\mu_{1}$ has been lowered from $4.61 \%$ to $75 \%$ of the risk free rate $r_{1}$, i.e. $2.17 \%$.

Table 2: Loglikelihoods, AIC and BIC for models with 2 to 5 states.

\begin{tabular}{|c|c|c|c|c|}
\hline & $N=2$ & $N=3$ & $N=4$ & $N=5$ \\
\hline LogLik. & 11446 & 11602 & $\mathbf{1 1 ~ 6 3 3}$ & 11630 \\
\hline AIC & -22879 & -23180 & $\mathbf{- 2 3} \mathbf{2 2 5}$ & -23200 \\
\hline BIC & -22940 & -23303 & $\mathbf{- 2 3} \mathbf{4 2 9}$ & -23506 \\
\hline
\end{tabular}

Table 3: Drifts, volatilities and standard errors of stocks log-returns, under the real measure $\mathbb{P}$, filtered from observations.

\begin{tabular}{|c|c|c||c|c|c|}
\hline & Estimate & Std Err. & & Estimate & Std Err. \\
\hline $\bar{\mu}_{1}$ & $7.21 \%$ & $0.23 \%$ & $\bar{\mu}_{2}$ & $6.93 \%$ & $0.40 \%$ \\
\hline $\bar{\mu}_{3}$ & $-3.70 \%$ & $0.87 \%$ & $\bar{\mu}_{4}$ & $-47.57 \%$ & $2.01 \%$ \\
\hline$\sigma_{1}$ & $6.82 \%$ & $0.41 \%$ & $\sigma_{2}$ & $12.85 \%$ & $0.61 \%$ \\
\hline$\sigma_{3}$ & $22.09 \%$ & $1.21 \%$ & $\sigma_{4}$ & $41.44 \%$ & $3.74 \%$ \\
\hline
\end{tabular}

Table 4: Matrix of one-year transition probabilities for $\delta(t)$ and standard errors.

\begin{tabular}{|c|l|l|l|l|}
\hline$p_{i, j}(0,1)$ & state 1 & state 2 & state 3 & state 4 \\
\hline state 1 & 0.9768 & 0.0220 & 0.0005 & 0.0007 \\
\hline Std Err & 0.0427 & 0.0013 & 0.0064 & 0.0002 \\
\hline state 2 & 0.0135 & 0.9638 & 0.0224 & 0.0003 \\
\hline Std Err & 0.0082 & 0.0521 & 0.0046 & 0.0052 \\
\hline state 3 & 0.0005 & 0.0357 & 0.9515 & 0.0123 \\
\hline Std Err & 0.0004 & 0.0003 & 0.0342 & 0.0002 \\
\hline state 4 & 0.0000 & 0.0015 & 0.0399 & 0.9586 \\
\hline Std Err & 0.0007 & 0.0012 & 0.0023 & 0.0861 \\
\hline
\end{tabular}

Table 5: Average $12 \mathrm{M}$ Libor, Esscher vector $\xi$, and drift of $X_{t}$ under $\mathbb{Q}$ in each regime, based on observations from 2001 to 2014.

\begin{tabular}{|l|c|c|c|l|c|}
\hline & Libor $12 \mathrm{M}$ & & Esscher vector, $\xi$ & & Adjusted EBIT growth, $\mathbb{Q}$ \\
\hline$r_{1}$ & $2.89 \%$ & $\xi_{1}$ & -5.5802 & $\mu_{1}$ & $2.17 \%\left(4.61 \%^{*}\right)$ \\
\hline$r_{2}$ & $2.43 \%$ & $\xi_{2}$ & -3.9280 & $\mu_{2}$ & $0.44 \%$ \\
\hline$r_{3}$ & $2.38 \%$ & $\xi_{3}$ & -0.1095 & $\mu_{3}$ & $-4.23 \%$ \\
\hline$r_{4}$ & $2.88 \%$ & $\xi_{4}$ & 2.2813 & $\mu_{4}$ & $-8.39 \%$ \\
\hline
\end{tabular}


To emphasize interconnections between the capital structure and fair costs of liabilities, the bank is assumed to be founded at time $t=0$, when the economy is in State 3 (economic slow down). The initial value $x_{0}$ of $X_{t}$ is computed such that the asset value $A_{0}$ is equal to 100 . The purchase of the asset is financed by equity, CoCo bonds, straight bonds and deposits. Shareholders and depositors both invest 15 when the bank is created. Various allocations between straight and convertible debts are considered, for a total of $C C D_{0}+S D_{0}=70$, such that the accounting balance sheet is well balanced. Table 6 exhibits other parameters.

Table 6: Other parameters.

\begin{tabular}{|c|c|c|c|}
\hline$x_{0}$ & 1.2221 & $\lambda$ & $50 \%$ \\
\hline$A_{0}$ & 100 & $\gamma$ & $33 \%$ \\
\hline$E_{0}$ & 15 & $\theta$ & $50 \%$ \\
\hline$C D_{0}$ & 15 & $\delta(0)$ & 3 \\
\hline$N_{C}$ & $C C D_{0}$ & $N_{S}$ & $E_{0}$ \\
\hline
\end{tabular}

Table 7 shows the fair interests computed following procedures detailed in Section 8. First, it is interesting to notice that the total of interests paid, $\pi_{1}+\pi_{2}$, decreases slightly with the amount of CoCo bonds, from $C C D_{0}=65$ to 25 . The smallest charge of interests is around 5.09 and is greater than the initial earnings, $e^{x_{0}}=3.39$. The income after tax and interest expenses is thus negative just after the creation of the firm. Even if the total interest charge does not vary much, a closer look reveals huge spreads between yields of liabilities, as illustrated in the left sub-figure of Figure 9.1. This graph emphasizes that the higher the volume of CoCo debts is, the lower the cost of straight debts is, and the higher the yields of CoCo bonds and deposits are. These trends are directly related to different exposures to default risk. A bank, which is mainly financed by CoCo bonds, owns a comfortable cushion of capital to absorb potential losses. It has then a low probability of default, contrary to a bank heavily leveraged by straight debts. Later in this paragraph, the analysis of probabilities of bankruptcy will confirm this point. With the risk of bankruptcy reduced in this way, the default risk premium for straight debts is thus small. On the other hand, the deposit insurance is cheap and has a small impact on the yield of deposits, which is closer to the one of straight debts. However, the risk of conversion being high in this scenario, CoCo bonds are well remunerated. Another important factor implied in the calculation of CoCo rates is the conversion rate $\frac{N_{C}}{N_{C}+N_{S}}$. A sensitivity analysis to this conversion ratio concludes this section.

Table 7: Costs of liabilities per category in percentage and absolute value.

\begin{tabular}{|c|c|c|c|c|c|c|c|c|c|}
\hline$C C D_{0}$ & $S D_{0}$ & $C D_{0}$ & $\begin{array}{c}\text { Deposits } \\
\text { rate \% }\end{array}$ & $\begin{array}{c}\text { Straight debts } \\
\text { rate \% }\end{array}$ & $\begin{array}{c}\text { CoCo } \\
\text { rate \% }\end{array}$ & $\pi_{1, d}$ & $\pi_{1, s d}$ & $\pi_{2}$ & $\pi_{1}+\pi_{2}$ \\
\hline 65 & 5 & 15 & $3.32 \%$ & $4.47 \%$ & $7.80 \%$ & 0.4986 & 0.2235 & 5.0724 & 5.7945 \\
60 & 10 & 15 & $3.26 \%$ & $4.64 \%$ & $7.86 \%$ & 0.4891 & 0.4644 & 4.7148 & 5.6684 \\
55 & 15 & 15 & $3.20 \%$ & $4.83 \%$ & $7.90 \%$ & 0.4800 & 0.7252 & 4.3467 & 5.5519 \\
50 & 20 & 15 & $3.14 \%$ & $5.05 \%$ & $7.93 \%$ & 0.4709 & 1.0094 & 3.9628 & 5.4431 \\
45 & 25 & 15 & $3.08 \%$ & $5.29 \%$ & $7.91 \%$ & 0.4617 & 1.3227 & 3.5573 & 5.3417 \\
40 & 30 & 15 & $3.02 \%$ & $5.58 \%$ & $7.81 \%$ & 0.4523 & 1.6737 & 3.1229 & 5.2490 \\
35 & 35 & 15 & $2.95 \%$ & $5.93 \%$ & $7.56 \%$ & 0.4424 & 2.0772 & 2.6494 & 5.1689 \\
30 & 40 & 15 & $2.87 \%$ & $6.40 \%$ & $7.06 \%$ & 0.4316 & 2.5613 & 2.1176 & 5.1106 \\
25 & 45 & 15 & $2.79 \%$ & $7.10 \%$ & $5.92 \%$ & 0.4190 & 3.1970 & 1.4803 & 5.0963 \\
20 & 50 & 15 & $2.65 \%$ & $8.80 \%$ & $2.13 \%$ & 0.3987 & 4.3979 & 0.4267 & 5.2232 \\
\hline
\end{tabular}

Table 8 shows the economic value of the firm, which is the sum of all liabilities and equity, minus the deposits insurance, $F_{0}=100-D I_{0}$. Any increase of straight debts raises both the probability of default and the cost of deposits insurance. The firm's value is then systematically 
lower for banks that are highly leveraged by straight debts. In this model, it is clear that deposits insurance represents a friction in the market. Indeed, without this compulsory insurance, the firm's value would be independent from the capital structure, as stated in the Modigliani and Miller's theorem (1958).

Table 8 also provides the market value of equity and gross of insurance, in the current economic state (column $S_{0}$ ) and in other economic regimes, assuming that a transition to these states occurs immediately after the bank's birth. The right sub-figure of Figure 9.1 reveals that except state 3 , the equity curves are concave and admit maximum values at the level of straight debts around 45. Liabilities being issued at fair prices in state 3, the shareholders' equity is constant and equal to 15, whatever the capital structure of the bank. Our switching regime model emphasizes that this is no more the case if the economic conjuncture changes. From the shareholder's perspective, there exists an optimal structure of debts maximizing the equity value in economic regimes, different from the one in force, during the issuance of debts. This aspect should be taken into consideration for determining the bank's capital structure. More surprisingly, the equity value is slightly higher when the economy is highly depressed (fourth regime) than in slow down mode (third regime). This is explained by the parameters driving $X_{t}$ in these states, under the risk neutral measure. A quick calculation shows that the expected growth rate of $A_{t}$ under $\mathbb{Q}$,

$$
\begin{aligned}
& \mathbb{E}\left[\frac{A_{t}}{A_{0}} \mid \delta(s)=e_{3}, \forall s \in[0, t]\right]=e^{\left(\mu_{3}+\frac{1}{2} \sigma_{3}^{2}\right) t}=e^{-1.79 \% t}, \\
& \mathbb{E}\left[\frac{A_{t}}{A_{0}} \mid \delta(s)=e_{4}, \forall s \in[0, t]\right]=e^{\left(\mu_{4}+\frac{1}{2} \sigma_{4}^{2}\right) t}=e^{0.20 \% t},
\end{aligned}
$$

which is greater in state 4 than that in state 3 , because the volatility $\sigma_{4}$ is important. This means that once financial markets enter into recession (state 3), economic agents price assets with a very pessimistic set of assumptions. Whereas when the economy hits rock bottom (state 4 ), assets are valued with an assumption of high volatility and of soft growth ${ }^{4}$.

Table 8: Firm values, and equity values.

\begin{tabular}{|c|c|c|c|c|c|c|}
\hline $\begin{array}{c}\text { Straight Debts } \\
S D_{0}\end{array}$ & $\begin{array}{c}\text { Equity } \\
S_{0}, \delta(0)=e_{3}\end{array}$ & $\begin{array}{c}\text { Insurance } \\
D I_{0}\end{array}$ & $\begin{array}{c}\text { Firm Value } \\
F_{0}\end{array}$ & $\begin{array}{c}S_{0+}^{I}, \\
\delta(0+)=e_{1}\end{array}$ & $\begin{array}{c}S_{0+}^{I}, \\
\delta(0+)=e_{2}\end{array}$ & $\begin{array}{c}S_{0+}^{I}, \\
\delta(0+)=e_{4}\end{array}$ \\
\hline 5 & 18.8450 & 3.8449 & 96.1551 & 70.4433 & 33.9132 & 16.0851 \\
10 & 19.4680 & 4.4678 & 95.5322 & 73.7005 & 35.4458 & 16.6480 \\
15 & 20.0725 & 5.0724 & 94.9276 & 76.5372 & 36.8432 & 17.2506 \\
20 & 20.6708 & 5.6706 & 94.3294 & 79.0631 & 38.1159 & 17.8903 \\
25 & 21.2735 & 6.2734 & 93.7266 & 81.3247 & 39.2546 & 18.5618 \\
30 & 21.8928 & 6.8927 & 93.1073 & 83.3196 & 40.2284 & 19.2551 \\
35 & 22.5452 & 7.5450 & 92.4550 & 84.9815 & 40.9728 & 19.9482 \\
40 & 23.2591 & 8.2590 & 91.7410 & 86.1309 & 41.3633 & 20.5899 \\
45 & 24.1029 & 9.1028 & 90.8972 & 86.3038 & 41.1387 & 21.0391 \\
50 & 25.4674 & 10.4673 & 89.5327 & 83.4463 & 39.4691 & 20.4754 \\
\hline
\end{tabular}

\footnotetext{
${ }^{4}$ Decreasing the volatility $\sigma_{4}$ from $41.44 \%$ to $31.44 \%$, leads to an asset growth rate equal to $\left(\mu_{4}+\frac{1}{2} \sigma_{4}^{2}\right)=-$ $3.45 \%$ and for this volatility, the equity is lower in state 4 than in state 3 .
} 

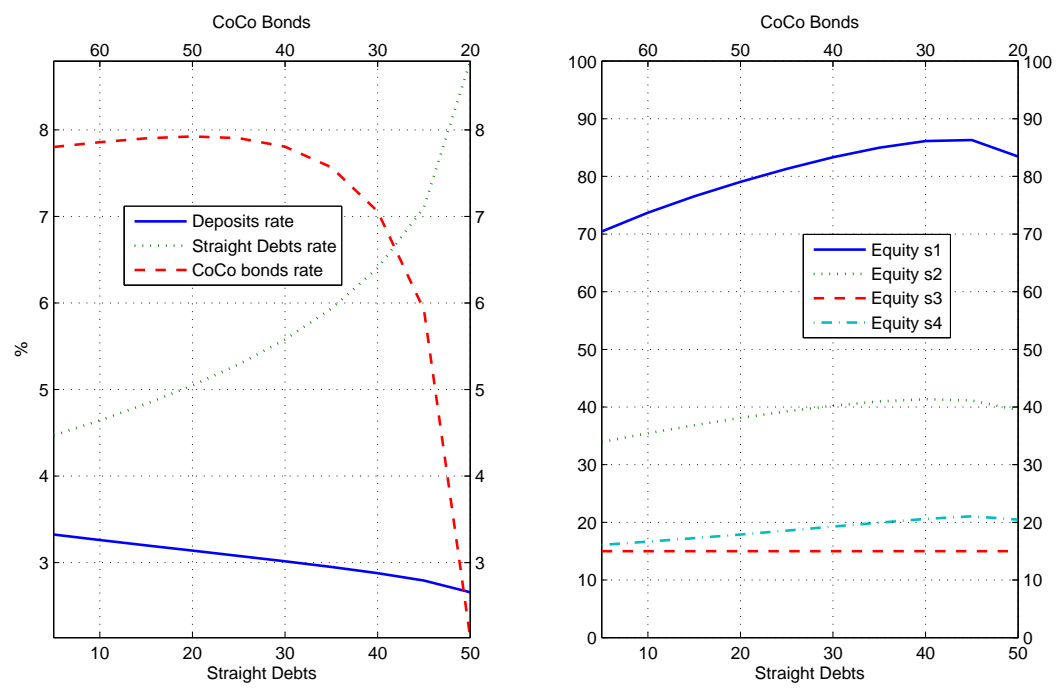

Figure 9.1: Cost of liabilities and Equity in each economic regime.

Although financing by a contingent convertible debt is an efficient way for a bank to mitigate the bankruptcy risk, it introduces a risk of dilution. In case of conversion of a massive convertible debt, former shareholders can avoid bankruptcy at the cost of losing control of the firm. In Section 7, indicators have been introduced to monitor these risks. Figure 9.2 plots the expected time before conversion against the average lifetime before ruin for several allocations of liabilities. In the particular case studied, the conversion occurs in average between 14 to 27 years, whereas the expected life time varies between 33 and 240 years. Here, expected times are computed under the risk neutral measure $\mathbb{Q}$ and earnings grow slower than the risk-free rate. Replacing risk neutral drifts by historical returns would immediately modify the value of these indicators. A bank highly leveraged by CoCo bonds has a longer expected lifetime and a lower probability of bankruptcy than a firm mainly financed by straight debts. But the shareholders' voting rights are diluted on average after a short period of time. This observation is confirmed by Figure 9.3, which presents the probabilities of bankruptcy and conversion from 1 to 50 years.

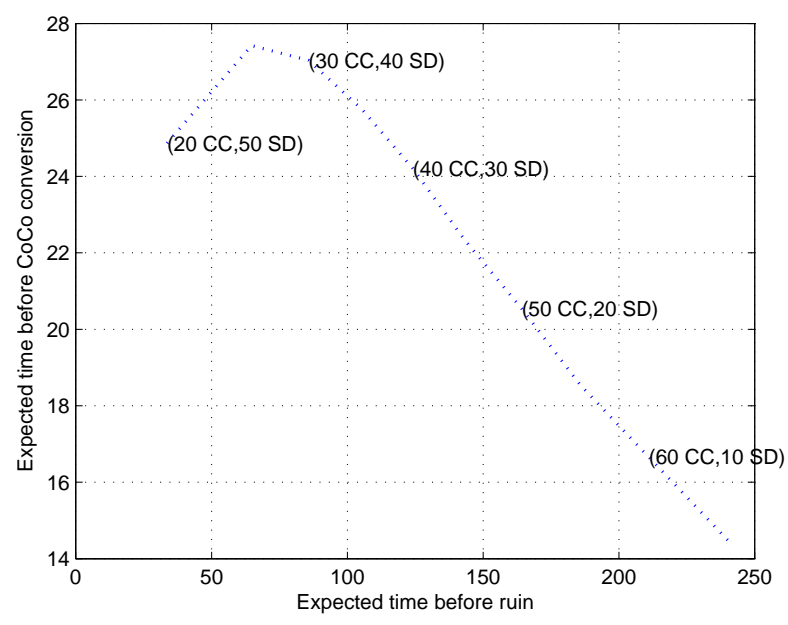

Figure 9.2: Expected time before ruin against average time before CoCo conversion. 

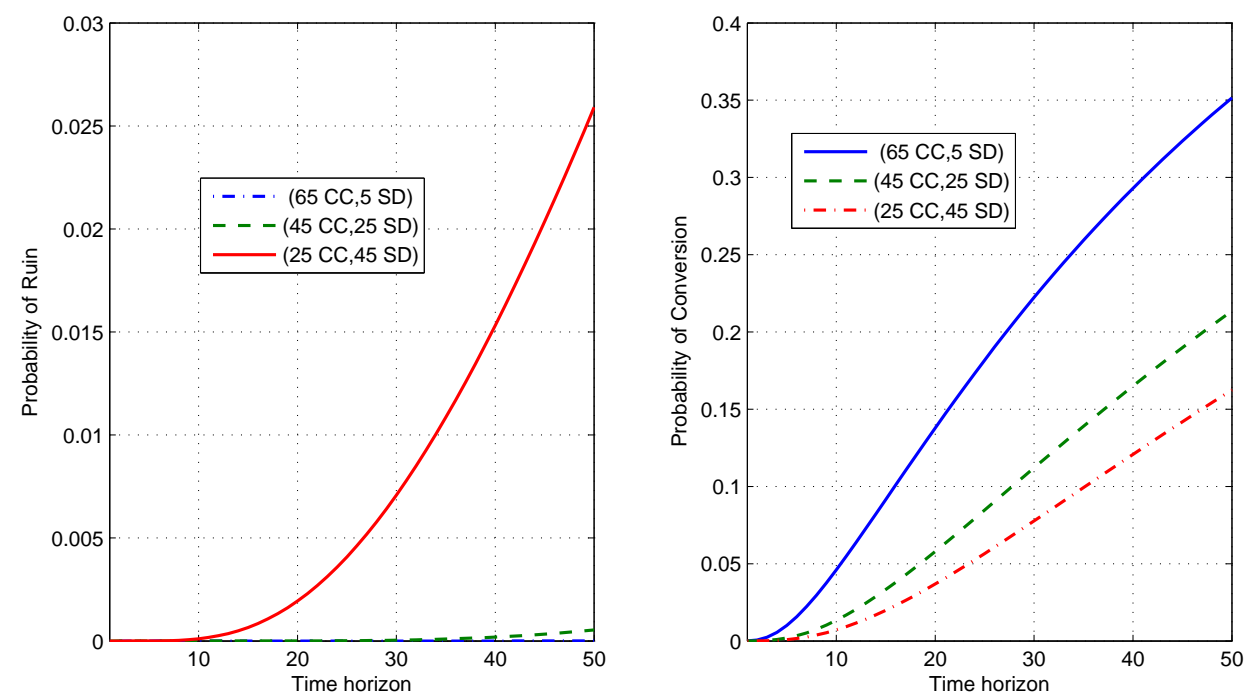

Figure 9.3: Probabilities of conversion and bankruptcy, per time horizon.

Table 9 analyzes the sensitivity of the fair cost of contingent debts to the conversion ratio, $\frac{N_{C}}{N_{C}+N_{S}}$ and shows that CoCo bonds with a higher conversion ratio are cheaper than those with a lower one. Intuitively, a lower conversion rate gives the right to a smaller fraction of earnings after conversion. To compensate this shortfall, the fair coupon paid before conversion is higher. The left graph of Figure 9.4 illustrates that the CoCo coupon declines monotonically with its conversion rate. And the right graph of the same figure shows the probabilities of swapping the CoCo bond to equity for different conversion rates. Paradoxically, for higher conversion ratios, the probabilities are significantly lower and the expected time before the swap is also longer. This is in fact a direct consequence of lower CoCo rates. If the bank issues CoCo with a high conversion ratio, the immediate total interest charge $\pi_{1}+\pi_{2}$ is low and the average delay before swapping the convertible into equity is lengthened. Probabilities of default are not reported because the likelihood of a default is not affected by the conversion rate in this extreme case.

Table 9: Impact on conversion rate on pricing of CoCo bonds. $S D_{0}=30, C C D_{0}=40$.

\begin{tabular}{|c|c|c|c|}
\hline Conversion rate, $\frac{N_{C}}{N_{C}+N_{S}}$ & CoCo rate, $\frac{\pi_{2}}{C C D_{0}}$, & $\mathbb{E}\left(\tau_{1} \mid \mathcal{F}_{0}\right)$ & $\mathbb{P}\left(\tau_{1} \leq 10\right.$ year $\left.s\right)$ \\
\hline 0.6500 & $10.31 \%$ & $7.11 \mathrm{y}$ & $18.62 \%$ \\
0.7000 & $8.34 \%$ & $20.10 \mathrm{y}$ & $1.84 \%$ \\
0.7500 & $7.45 \%$ & $27.03 \mathrm{y}$ & $0.74 \%$ \\
0.8000 & $6.85 \%$ & $31.97 \mathrm{y}$ & $0.40 \%$ \\
0.8500 & $6.38 \%$ & $36.41 \mathrm{y}$ & $0.25 \%$ \\
0.9000 & $6.00 \%$ & $39.91 \mathrm{y}$ & $0.17 \%$ \\
\hline
\end{tabular}



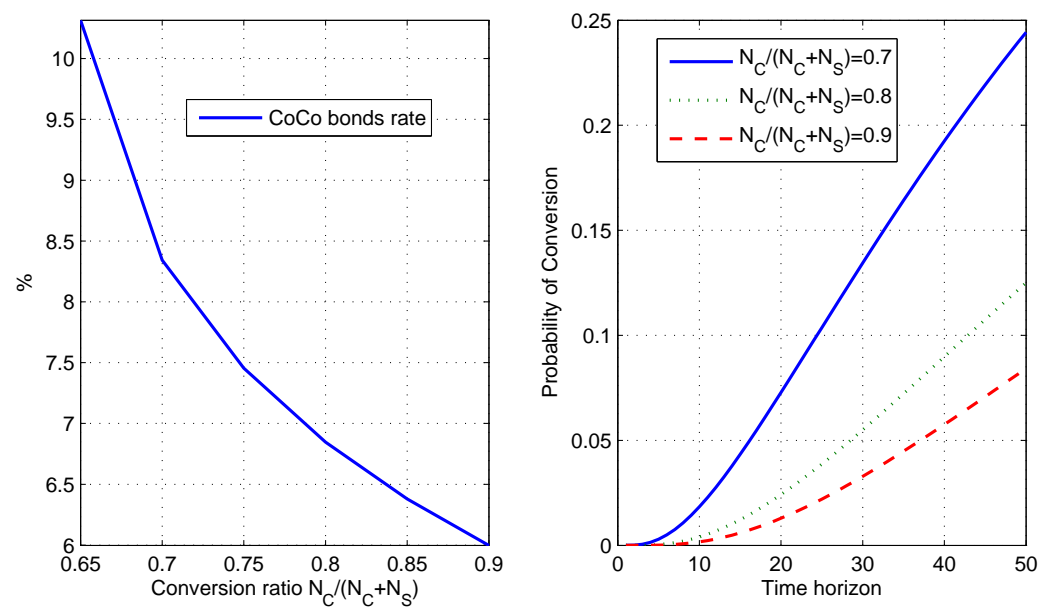

Figure 9.4: Probabilities of conversion and bankruptcy, per time horizon.

\section{Conclusions}

This paper emphasizes the link between the capital structure of a bank and the fair costs of its liabilities, when the operating profit is affected by variations of macroeconomic conditions. Contingent convertibles automatically recapitalize the financial institution in difficult times and are thus efficient instruments to mitigate the risk of bankruptcy. Furthermore, numerical analysis shows that a high volume of convertible debts reduces the yield offered to straight debts. When the probability of default is lower, the cost of deposits insurance falls and depositors in counterpart receive a higher compensation. But it does not totally removed the risk of bankruptcy.

On the other hand, the risk of dilution is huge for shareholders. However, it is rather surprising that this risk can be mitigated by increasing the conversion rate of the convertible debt. If this debt is fairly priced, the high conversion rate is compensated by a low interest cost before conversion. The total financial charge and the probability that earnings fall below the regulatory threshold is reduced. This postpones on average the conversion of CoCo bonds into equity.

By construction, when liabilities are issued at fair prices, the shareholders' equity has a constant market value, whatever the capital structure of the bank. The switching regime model emphasizes that this is no more the case if the economic conjuncture changes. From the shareholder's perspective, there exists an optimal structure of debts maximizing the equity value in economic regimes, different from the one in force, during the issuance of debts. This aspect should be taken into consideration for optimizing the bank's capital structure.

\section{References}

[1] Abate J., Whitt. W. 2006. "A Unified Framework for Numerically Inverting Laplace Transforms." INFORMS Journal of Computing, 18.4 , 408-421.

[2] Ammann M. and Genser M. 2005. Making Structural Credit Risk Models Testable: Introducing Complex Capital Structures. University of St. Gallen, Working paper.

[3] Altman E. Resti A. Sironi A. 2002. The link between default and recovery rates: effects on the procyclicality of regulatory capital ratios. BIS Working Paper, 113. 
[4] Barucci E. Del Viva L. 2012. Countercyclical contigent capital. Journal of Banking \& Finance, 36, 1688-1709.

[5] Barucci E. Del Viva L. 2013. Dynamic capital structure and the contingent capital option. Annals of Finance, 9 (3), 337-364.

[6] Bradley M., Jarrell G.A , Kim E.H. 1984. On the existence of an optimal capital structure: theory and evidence. Journal of Finance, 39 (3), 857-878.

[7] Brennan, M., Schwartz E. 1978, Corporate income taxes, valuation, and the problem of optimal capital structure, Journal of Business 51, 103-114.

[8] Buffington J., Elliott R.J. 2002. American options with regime switching. International Journal of Theoretical and Applied Finance 5, 497-514.

[9] Calvet L., Fisher A. 2001. Forecasting multifractal volatility. Journal of econometrics. 105, $17-58$.

[10] Calvet L., Fisher A. 2004. How to forecast long-Run volatility: regime switching and the estimation of multifractal processes. Journal of Financial Economics 2, 49-83.

[11] Chen N. Kou S. 2009. Credit spreads, optimal capital structure and implied volatility with endogeneous default and jump risk. Mathematical Finance, 19 (3), 343-378.

[12] Cholette L., Heinen A., Valdesogo Al. 2009. Modelling international financial returns with a multivariate regime switching copula. Journal of financial econometrics 7 (4), 437-480.

[13] Corcuera J.M., De Spiegeleer J., Fajardo J., Jönsson H., Schoutens W., Valdivia A. Close form pricing formulas for Coupon Cancellable CoCos. Forthcoming Journal of Banking \& Finance, doi: http:// dx.doi.org/10.1016/j.jbankfin.2014.01.025 .

[14] De Spiegeleer J., Schoutens W. 2012. Steering a bank around a death spiral: Multiple Trigger CoCos. Wilmott Magazine 59, 62-69.

[15] De Spiegeleer J., Schoutens W. 2013. Multiple Trigger CoCos: Contingent debt without death-spiral risk. Financial Markets, Institution and Instruments Journal 22(2), 129-141.

[16] Elliott R. J., Chan L., Siu T. K. 2005. Option pricing and Esscher transform under regime switching. Annals of Finance 1, 423-432.

[17] Elliott R. J., Siu T. K. 2013. Option pricing and filtering with hidden Markov-modulated pure-jump processes. Applied Mathematical Finance 20(1), 1-25.

[18] Gatumel M., Ielpo F. 2011. The Number of Regimes Across Asset Returns: Identication and Economic Value. Working paper, available at SSRN 1925058.

[19] Gerber H.U., Shiu E.S.W. 1994. Options Pricing by Esscher Transform. Transactions of the society of actuaries, 26, 99-191.

[20] Glasserman P., Nouri B. 2012. Contingent Capital with a Capital-Ratio Trigger. Management Science,58 (10), 1816-1833

[21] Guidolin M., Timmermann A. 2005. Economic Implications of bull and bear regimes in UK stock and bond returns. The Economic Journal, 115, 11-143

[22] Guidolin M., Timmermann A. 2007. Asset allocation under multivariate regime switching. Journal of Economic Dynamics and Control, 31 (11), 3503-3544. 
[23] Guidolin M., Timmermann A. 2008. International Asset Allocation under Regime Switching, Skew, and Kurtosis Preferences. Review of Financial Studies. 21 (2), 889-935.

[24] Hackbarth D., Miao J., Morellec E. 2006. Capital structure, credit risk and macroeconomics conditions. Journal of Financial Economics. 82, 519-550.

[25] Hainaut D., MacGilchrist R. 2012 Strategic asset allocation with switching dependence. Annals of Finance 8 (1), 75-96.

[26] Hamilton J.D. 1989 "A New Approach to the Economic Analysis of Nonstationary Time Series and the Business Cycle." Econometrica. 57 (2), 357-384.

[27] Harding J., Liang X., Ross S.L. 2007. The optimal capital structure of banks: balancing deposit insurance, capital requirements and tax-advantaged debt. Working paper University of Connecticut.

[28] Hilberink B., Rogers L.C.G. 2002. Optimal capital structure and endogenous default. Finance and stochastics $6,237-263$.

[29] Jiang Z., Pistorius M.R. 2008. On perpetual American put valuation and first-passage in a regime-switching model with jumps. Finance and Stochastics, 12 (3), 331-355.

[30] Koziol C., Lawrenz J. 2012. Contingent convertibles. Solving or seeding the next banking crisis. Journal of Banking \& Finance, 36, 90-104.

[31] Leland H. 1994. Corporate debt value, bond covenants, and optimal capital structure. Journal of Finance 49, 1213-1252.

[32] Leland, H., and K. Toft, 1996, Optimal Capital Structure, Endogenous Bankruptcy, and the Term Structure of Credit Spreads, Journal of Finance 51, 987-1019.

[33] Leland H., 1998, Agency Costs, Risk Management, and Capital Structure, Journal of Finance $53,1213-1243$.

[34] Myers S. C. 1984. The Capital Structure Puzzle. Journal of Finance 39 (3), 575-592.

[35] Modigliani F., Miller M. 1958. The Cost of Capital, Corporation Finance and the Theory of Investment, American Economic Review 48, 261-297.

[36] Pennacchi G. 2010. A structural model of contingent bank capital. The federal Reserve Bank of Cleveland. Working paper.

[37] Rogers L., Shi Z. 1994. Computing the invariant law of a fluid model. Journal of Applied Probability, 31 (4), 885-896.

[38] Titman S., Wessels R. 1988. The determinants of capital structure choice. Journal of Finance $43(1), 1-19$.

[39] Titman S., Tsyplakov S. 2007. A Dynamic Model of Optimal Capital Structure. Review of Finance 11 (3), 401-451. 